\title{
La Gramática Cognitiva en los materiales de ELE: análisis y propuesta metodológica
}

\author{
CArles Navarro-CARrascosa \\ Universitat de València \\ carles.navarro@uv.es
}

\begin{abstract}
Resumen: La Gramática Cognitiva (en adelante, GC) es una de las propuestas metodológicas para la enseñanza de ELE que más presencia tiene en las aulas en la actualidad. Las editoriales se hacen eco de ello y en las últimas décadas son cada vez más los materiales que se elaboran adoptando este enfoque para la enseñanza de las estructuras gramaticales. Con este trabajo se pretende analizar la manera en la que estos manuales aplican los principios metodológicos de la GC y cómo pueden los docentes identificar cuáles lo hacen y en qué grado. Para ello, se propone una ficha de análisis que pretende detectar los puntos clave de la GC en los manuales. Posteriormente, se ha llevado acabo el análisis de algunos de los manuales más relevantes en la enseñanza de ELE, como son la Gramática básica del estudiante de español, Aula, Nuevo Prisma y ELE Actual.
\end{abstract}

Palabras clave: Gramática Cognitiva, análisis de materiales, metodología, español.

\section{Cognitive Grammar in Spanish as a foreign language manuals: analysis and methodological proposal}

Abstract: Cognitive Grammar is one of the methodological proposals for teaching Spanish that has most presence in classrooms today. Publishers have realized this, and more materials have been produced using this approach for teaching grammatical structures during the last twenty years. The aim of this work is to analyze the way that these manuals apply the methodological principles of Cognitive Grammar, and how teachers can identify them. Moreover, the impact of the Cognitive Grammar in those will be analyzed, in order to measure how much the methodology has defined their teaching structure. For this purpose, an analysis form has been proposed, created for the detection of the Cognitive Grammar key points mentioned before, which applied to manuals for learning Spanish as a foreign language.

Key words: Cognitive Grammar, materials analysis, methodology, Spanish.

\section{Introducción}

La Gramática Cognitiva es una tendencia metodológica en la enseñanza de lenguas extranjeras que se ha extendido considerablemente en las últimas décadas. Cada vez son más las y los docentes que recurren a este planteamiento teórico para presentar las estructuras gramaticales en el aula sin renunciar, por ello, al enfoque comunicativo.

Así, muchas editoriales se han hecho eco de esta tendencia y el número de manuales que adoptan los principios de la GC como metodología en sus explicaciones de las formas gramaticales ha aumentado. No obstante, cabe preguntarse cómo puede saber el/la docente que desea aplicar un enfoque cognitivo cuál es el manual que mejor se va a ajustar 
a sus necesidades y objetivos. Con este trabajo se pretende crear una ficha de análisis de manuales que reconozca el grado de integración de la GC para que el profesor que así lo desee pueda detectar con facilidad cuáles son los métodos más afines a esta. Además, se presenta el análisis de cuatro manuales de las principales editoriales especializadas en ELE, como son Gramática básica del estudiante de español y Aula 4, ambos de la editorial Difusión; Nuevo Prisma B1, de Edinumen; y ELE Actual B1, publicado por SM. Estos materiales han sido seleccionados por ser cuatro de los manuales más utilizados en los cursos de español.

Los cuatro manuales seleccionados están diseñados para el nivel B1. Este es el nivel que se ha escogido para la investigación, pues la gramática que se imparte cuenta en su haber con algunas de las estructuras gramaticales que más problemas suponen a los aprendientes de español (Llopis-García, Real Espinosa y Ruiz Campillo, 2012), como son los distintos tiempos de pasado de indicativo, así como la presentación de las principales formas verbales de subjuntivo (presente y pretérito imperfecto). Además, tanto los tiempos de pasado como el modo subjuntivo son estructuras a las que se han dedicado diversos trabajos redactados por los principales autores de la GC en ELE. Así, sobre los tiempos de pasado publicaciones como las de Real Espinosa (2005, 2013), Castañeda Castro (2006), Palacio Alegre (2016), Ruiz Campillo (2005, 2017), Cáceres Riquelme (2018), Funes y Poggio (2018) y Wilk-Racieska (2020) son algunas de las que podemos destacar; entre todos los estudios que se han elaborado acerca del subjuntivo y la GC, queremos subrayar los de Salas Díaz (2011), Ruiz Campillo (2007a y b, 2012, 2014), Llopis García $(2011,2019)$ y Solá Simon (2020). Todos estos trabajos, sus reflexiones y resultados, han facilitado el diseño de la ficha de análisis y el reconocimiento del planteamiento cognitivo de estas estructuras gramaticales, cuando este se daba.

\section{2. ¿Qué es la Gramática Cognitiva?}

En las últimas dos décadas, en la adquisición de segundas lenguas, se ha desarrollado un nuevo planteamiento que postula que la gramática es significativa. Esto implica que, al igual que cada palabra tiene un significante y un significado, en las formas gramaticales ocurre lo mismo. Por tanto, una estructura gramatical también puede funcionar como un armazón físico que alberga un significado.

Llopis-García, Real Espinosa y Ruiz Campillo afirman que plantear la gramática como significativa para el estudiantado mejorará el modo en el que este la asimile y esto debería hacerse «en los siguientes sentidos» (2012: 16):

a) Por un lado, debería exponer al estudiante a un significado gramatical de la forma, no a un número discrecional de significados contextuales, de manera que pudiera entender [...] el porqué de las formas que estudia.

b) Por otro lado, debería hacer responsable de las decisiones gramaticales al significado (decide según lo que quieres decir), no a la forma ( $\mathrm{X}$ rige $\mathrm{Y}$ ).

c) En general, y en todo caso, debería interactuar con los conocimientos del mundo que tengan tanto el profesor como los estudiantes [...].

La GC es, tal y como señalan estos autores (2012: 22), «una gramática de relación indisoluble entre forma y significado» que lo que pretende es hacer que el estudiante entienda el significado de las formas gramaticales, evitando, de esta forma, que tenga que memorizar las tradicionales listas de usos. 
Para ofrecer un ejemplo concreto y poder explicar los parámetros fundamentales de la GC en ELE, desarrollaremos los estudios que se han desarrollado sobre las preposiciones. Lam (2009: 4), apunta que «la lingüística cognitiva cree que los múltiples usos de las preposiciones están en cierto modo relacionados entre sí con el fin de dar cuenta de por qué los hablantes eligen una misma forma para expresar estos significados» ${ }^{1}$. Siguiendo esta idea y para trabajar las preposiciones dentro del marco de la GC, resultan de interés dos conceptos básicos: la teoría de los prototipos y la metáfora del espacio (Llopis-García, 2015). La teoría de los prototipos propone que

categorizamos la realidad de acuerdo con la semejanza de cada objeto con el miembro central de su categoría. Este miembro central es [...] el "el mejor ejemplo" de la categoría. Los "mejores" ejemplos serán aquellos que les vengan a la mente con mayor facilidad a los hablantes nativos de una lengua. (Llopis-García, 2015: 56)

En el caso de las preposiciones, los mejores ejemplos serán aquellos que la mayoría de hablantes emitan cuando se les pida un enunciado con esa preposición. Es decir, si se le pide a un hablante que piense en un ejemplo de la preposición por, en la mayoría de los casos se le vendrá a la mente una oración como paseo por el parque; si se le pide uno de para, pensará en enunciados de tipo ve para casa; en ambos casos, ejemplos espaciales.

Por otro lado, la metáfora es un pilar indiscutible para la GC. Lakoff y Johnson argumentan a lo largo de su obra que la metáfora no se limita solo al lenguaje retórico, sino que en nuestro lenguaje diario, el del día a día, el número de metáforas que son utilizadas es muy alto: «Nuestro sistema conceptual ordinario en términos del cual pensamos y actuamos, es fundamentalmente de naturaleza metafórica» (1986: 39). Y las metáforas, por lo general, se basan en los conceptos espaciales, que serían los originales y primeros (el prototipo), pues «el ser humano domina el espacio mucho antes de que la lengua empiece a tomar forma en el cerebro y ese dominio se va a reflejar en cómo representa los pensamientos lingüísticamente al aprender a hablar» (Llopis-García, 2015: $57)$.

Tanto la Teoría de los prototipos como la Metáfora del espacio buscan reducir las listas de usos y significados de las formas gramaticales y encontrar el significado prototípico de cada forma, con el fin de facilitar el aprendizaje y hacerlo más significativo y operativo para los aprendientes.

Llopis García (2015) ejemplifica la aplicación de la Teoria de los prototipos y la Metáfora del espacio para la enseñanza de ELE desde un punto de vista cognitivo con la preposición para.

Teniendo en cuenta que el prototipo siempre va a tomar la perspectiva del espacio, un ejemplo central posible para esta preposición sería: voy para mi casa, ¿quieres algo?, donde se implica la dirección general de mi casa, pero no se presupone que la persona vaya a completar el recorrido completo, y probablemente antes vaya a otro lugar distinto. Por medio de la extensión semántica metafórica, este valor central se aplica a casos tan diversos como:

Te lo digo para que aprendas - donde hay una relación lineal entre decir y aprender, pero no se da por hecho el aprendizaje de la otra persona [...].

He comprado un regalo para mi madre - donde hay una relación directa entre el regalo y el receptor, mi madre. Sin embargo, por el contenido de la frase no queda implícito, como tampoco lo hace el prototipo, si se lo he dado o no, si ya lo tenía, o si lo tendrá en algún momento.

\footnotetext{
${ }^{1}$ Traducción propia: «cognitive linguistics believe that the multiple uses of prepositions are somehow related to each other in order to account for why speakers choose the same form to symbolise these meanings».
} 
Para mí, que Luis y Eva son pareja -donde la relación entre mi opinión y la realidad de Luis y Eva no queda confirmada por completo, no cierra la presuposición y, por tanto, me libera a mí de comprometer mi palabra [...].

Por tanto, y aunque a veces parezca haber mucha distancia entre el prototipo y un uso determinado, las redes semánticas y las metáforas empleadas para ir de uno a otro siempre tendrán una razón de ser y podrán cobrar sentido para los hablantes. (Llopis-García, 2015: 62)

Además, según esta autora, hacer visibles estas redes semánticas y trabajar con ellas a la hora de abordar la gramática en clase de ELE, «reduce la arbitrariedad de usos [...] y ayuda a los estudiantes a categorizar y ordenar las instancias» de las estructuras gramaticales (2015: 64). Este es el enfoque que se rastreará en los manuales que analizamos.

\section{Señas de la GC en los manuales de ELE}

Desde un punto de vista estrictamente práctico, pero sin desatender lo expuesto en el apartado anterior, es importante mencionar las distintas formas de aplicar la GC de una forma práctica en el aula de ELE, para poder identificar estos rasgos en los manuales y categorizar sus metodologías como cognitivas (si siguen los planteamientos de la GC) o no.

El foco de atención serán las estructuras gramaticales; por tanto, debemos centrarnos en dos modalidades: cómo son presentadas estas estructuras y cómo se plantean las actividades en las que se ejercitan.

\subsection{Presentación de las formas gramaticales}

Muchos de los estudiosos de GC aplicada a la enseñanza del español son partidarios de la propuesta de Long $(1988,1991,2007)$ llamada Atención a la forma (Focus on form, en inglés), como sugieren los trabajos de Llopis-García, Real Espinosa y Ruiz Campillo (2012), Miquel y Ortega (2014), Casellas Guitart (2014), LLopis-García (2015), entre otros. La Atención a la forma (AF, en adelante) propone

dirigir la atención del estudiante hacia la gramática como respuesta a una necesidad o problema comunicativo surgido durante la realización de una de esas tareas. [...] sugiere trabajar una estructura concreta como reacción a una dificultad comunicativa concreta y en un contexto comunicativo concreto. (Alonso Aparicio, 2014: 12)

Es un enfoque de enseñanza gramatical que pretende ser comunicativo. Se trata de que el estudiante registre de forma consciente y asimile la estructura gramatical que se esté instruyendo para poder comunicarse con efectividad y resolver problemas comunicativos que surjan en contextos de habla. Para ello, la enseñanza de la gramática debe centrarse en las propias estructuras y en los significados de estas, planteados como significados operativos que permitan que el estudiante escoja la mejor forma, atendiendo a sus objetivos para la comunicación. La captación de la forma gramatical y su significado operativo será el objetivo de la enseñanza (Alonso Aparicio, 2014).

La AF propone varias técnicas didácticas, de las que destacamos tres: «reformulaciones correctivas o solicitudes de clarificación [...], el input realzado tipográficamente [...] y el input anegado o enriquecido (proporcionar múltiples muestras de la estructura meta).» (Alonso Aparicio, 2014: 13) 
Atendiendo a estas cuestiones, sobre la presentación de la forma gramatical objeto de la instrucción en los manuales, hay que atender a los siguientes puntos: el lugar en el que aparece la explicación (antes o después del primer input); los usos y las excepciones de esta estructura; si se aportan imágenes para esta explicación; y la presentación del input.

En primer lugar, resultará relevante el lugar en el que aparecen las explicaciones gramaticales: antes o después del primer input. Esta cuestión se relaciona con el tipo de instrucción que se plantea a través del planteamiento de la AF. Es decir, si se presenta un enfoque inductivo, en el que el estudiante debe tratar de dilucidar el funcionamiento y el significado de la forma gramatical a partir de los usos que ha observado en el input presentado; o si se plantea un enfoque deductivo, en el que se presenta primero la forma gramatical y, posteriormente, el discente debe tratar de comprender su funcionamiento y aplicarlo en las actividades que se plantean. Ambos enfoques son característicos de los materiales que adoptan la GC.

En segundo lugar, cabe observar si estas explicaciones gramaticales presentan diversos usos de la estructura gramatical y excepciones de estos; una única norma y excepciones; o una única regla general para todos los posibles usos de la forma gramatical que se presenta para la instrucción. El objetivo de la GC es ofrecer un único significado operativo de cada estructura gramatical que pueda funcionar en todos los posibles contextos de uso, por lo tanto, hablar de excepciones y/o de una regla general (de la que se derivan reglas excepcionales) es contraproducente con esta idea $y$, consecuentemente, va en contra de los principios de la GC.

Siguiendo estos principios, también se busca analizar el tratamiento que se da a formas gramaticales que pueden contrastar. Por ejemplo, si se trabajara la diferencia entre el pretérito perfecto y el pretérito indefinido, buscaríamos si la distinción entre ambas formas se limita a cuestiones formales (como, por ejemplo, los conectores que acompañan a cada una) o si se incide en el significado operativo de cada una para que los estudiantes puedan aprender a utilizarlas para resolver problemas.

En tercer lugar, se debe revisar si se aportan imágenes para facilitar la comprensión de la gramática. La imagen puede funcionar a modo de representación gramatical «fundamentalmente como una noción teórica de la GC con la que se puede dar cuenta de muchas distinciones formales de la gramática del español» (Castañeda y Alhmoud, 2014: 77). Las imágenes, además, pueden ayudar a la comprensión de conceptos abstractos y significados metafóricos. Es por ello que los cognitivistas recurren a este elemento de apoyo y, por tanto, es considerado uno de los elementos fundamentales dentro de los manuales que pretendan integrar la $\mathrm{GC}$ en sus explicaciones de gramática. Es por ello que hay que analizar si las ilustraciones ofrecen algún tipo de explicación o, simplemente, cumplen una función decorativa.

En cuarto y último lugar, debe analizarse el tratamiento que se le da al input en los distintos manuales. Así, se revisará la tipografía, el tipo de enunciados y el objetivo de estos.

Como la AF quiere centrar la atención en las propias formas gramaticales para desarrollar los conocimientos sobre las mismas y que la instrucción gire en torno a esto, lo habitual y recomendable es que las formas aparezcan resaltadas de alguna forma particular, bien usando negrita, cursiva, un color diferente al resto del enunciado o cualquier otro recurso que pueda destacar la estructura visualmente. 
Además, el input presentado debe estar basado, preferiblemente, en ejemplos de habla verosímiles y no enunciados forzados, poco o nada susceptibles de ser emitidos por hablantes nativos. Esto no implica que los ejemplos que se planteen sean muestras reales de uso (incluso si lo son, pueden estar adaptados al nivel de instrucción), sin embargo, sí que deben simular un contexto comunicativo real. De esta manera, el significado operativo de las formas cobrará sentido para el discente y su asimilación será más exitosa.

De la misma manera y en relación con lo dicho previamente, el único objetivo de los enunciados del input debe ser poder ilustrar y ejemplificar el significado operativo de las formas gramaticales, así como su uso en diferentes situaciones.

\subsection{Actividades}

Como ya hemos señalado antes, la GC considera que la gramática es «una respuesta a un problema comunicativo surgido durante la realización de una tarea» (Alonso, 2014: 12), y es así como se pretenden plantear las actividades. Para trabajar la forma gramatical como herramienta para resolver una dificultad comunicativa concreta, se proponen los siguientes cuatro puntos:

- La forma gramatical se plantea como la solución al problema que se presenta en la actividad.

- Las actividades son, o simulan ser, una interacción comunicativa.

- Los estudiantes deben darse cuenta de la existencia de la forma gramatical (captación de la forma).

- Para ello, el input está realzado tipográficamente y con múltiples muestras (Long y Robinson, 1998; Fernández Montes, 2011).

Siguiendo estas directrices, el análisis de las actividades gramaticales que se plantea para los manuales debe tener en cuenta si las actividades son de práctica libre o de práctica controlada. Las actividades de práctica libre son actividades en las que se dan pocas instrucciones $\mathrm{y}$, generalmente, el estudiante puede utilizar el vocabulario y los recursos gramaticales que crea oportunos, sin que haya nada en concreto que trabajar o, si lo hay, no se dan indicaciones sobre cómo debe ser utilizado este recurso. Por otro lado, las actividades de práctica controlada son aquellas que esperan una producción por parte del estudiante, pero esta debe llevarse a cabo siguiendo unas instrucciones para que se cumplan determinados objetivos. Con este último tipo de actividades se espera que el estudiante pueda utilizar una forma gramatical (o varias) para cumplir unos fines que se le han marcado y, así, mientras realiza la tarea, está interiorizando el uso y el significado de esta estructura. Es por ello que este es el tipo de ejercicios que se generan dentro del enfoque cognitivo, pues son los únicos que pueden centrarse en las estructuras gramaticales.

Posteriormente, también debe analizarse la progresión de las actividades. Cuando hablamos de la AF insistimos en que la estructura gramatical debe ser el eje de la instrucción, sin embargo, no nos referimos a que el aprendizaje debe partir de la memorización de la forma regular e irregular de determinadas estructuras, si no a que el aprendizaje debe centrarse en asociar determinados significados a determinadas formas, y después, una vez esto esté interiorizado, es cuando se debe proceder al aprendizaje 
estrictamente formal: primero, entender la forma; después, memorizarla. Así, las actividades deben presentar una progresión en la que primero se pone el foco en el contenido o en el significado de las formas y, después, se incide, poco a poco, en su construcción.

También se debe centrar la atención en el tipo de actividades que se plantean, siguiendo la clasificación de las actividades de la AF que hacen Miquel y Ortega (2014): de interpretación gramatical o de producción.

Sobre las actividades de interpretación gramatical, estas pueden ser de input estructurado o de toma de conciencia gramatical.

Las primeras son actividades que trabajan con un input en cierto modo reestructurado para que se pueda hacer un procesamiento bien preciso tanto de la forma como de su significado (Van Patten, 2007). Estas actividades pretenden proporcionar información a los estudiantes «sobre el elemento lingüístico que va a ser objeto de atención» (Miquel y Ortega, 2014: 124). De las líneas generales para el desarrollo de este tipo de actividades, destacamos tres: se debe presentar un contenido por vez; se debe ir de las oraciones a un discurso más amplio; y los estudiantes deben tener que trabajar con ese input.

Con las actividades de conciencia gramatical «se persigue la obtención del conocimiento explícito sobre un recurso gramatical» (Miquel y Ortega, 2014: 100). No buscan que el aprendiente produzca output, aunque puede ocurrir. Lo que se pretende con estas actividades es el reconocimiento y la interpretación de algunas estructuras y, por tanto, deben disponer de input «debidamente contextualizado y comunicativamente ajustado» (Miquel y Ortega, 2014: 100), es decir, actividades de input estructurado. De estas, se pueden diferenciar dos tipos:

- Inductivo: el conocimiento y el funcionamiento de la forma gramatical lo obtienen los aprendientes inductivamente, es decir, interpretando lo que hace la forma a partir de la observación del input. Por ejemplo, una actividad en la que el objetivo es que el aprendiente entienda la diferencia entre el pretérito perfecto y el pretérito indefinido mostrará varios ejemplos de uso de ambos tiempos. Tras observar el input propuesto, el estudiante deberá interpretar el uso de cada forma. El siguiente ejemplo ilustra este tipo de actividad:
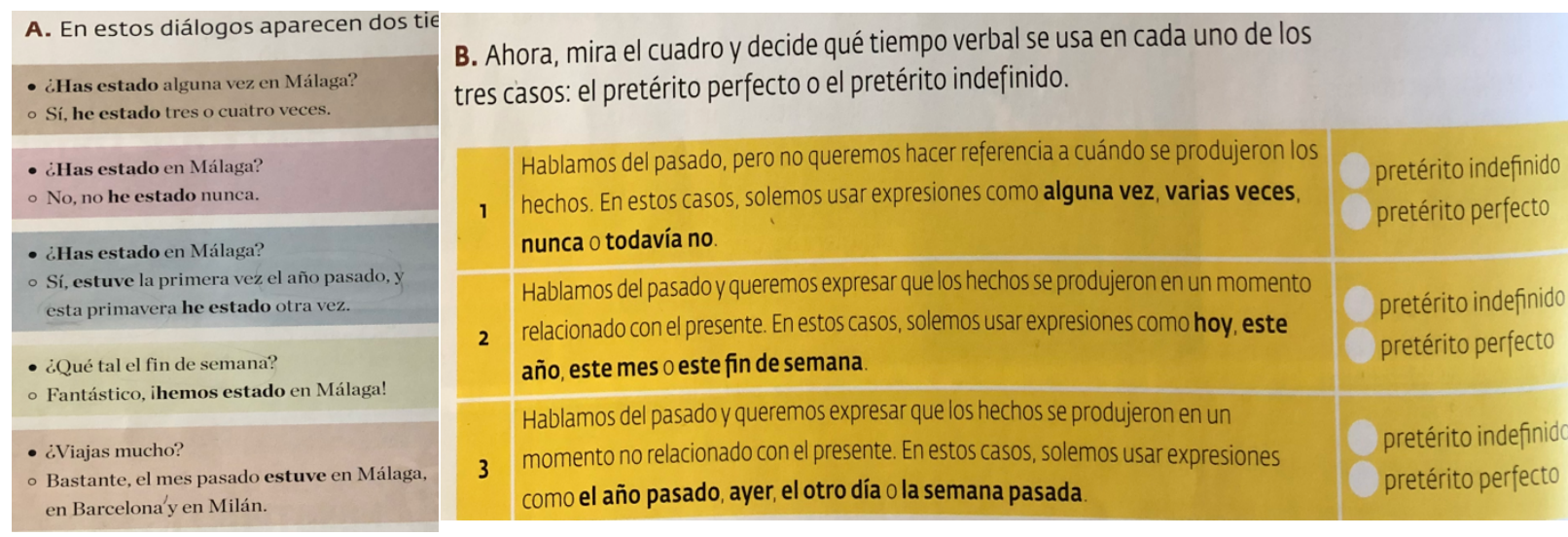

Imagen 1. Actividad de conciencia gramatical de tipo inductivo con input estructurado. Aula 2 (Difusión) 
- Deductivo: Tras ser «presentado de manera explícita el mecanismo gramatical, los aprendientes emprenden la tarea de aplicar este conocimiento a la comprensión y a la organización de ciertos datos presentes en el input proporcionado» (Miquel y Ortega, 2014: 100). El aprendiente ya dispone de la información gramatical necesaria, por lo que la actividad consistirá en practicar aquello que acaba de aprender.

Las actividades de producción pueden ser de output estructurado o de gramaticalización. Las primeras se centran en un solo aspecto gramatical que servirá para expresar contenido. Son actividades que están planteadas de tal manera que se espera una determinada respuesta: se proponen problemas (huecos, preguntas...) cuyas soluciones vienen por el uso de determinadas formas previamente presentadas. De esta manera, el output que debe generar el aprendiente está orientado por el planteamiento de la actividad, como se puede ver en el siguiente ejemplo:

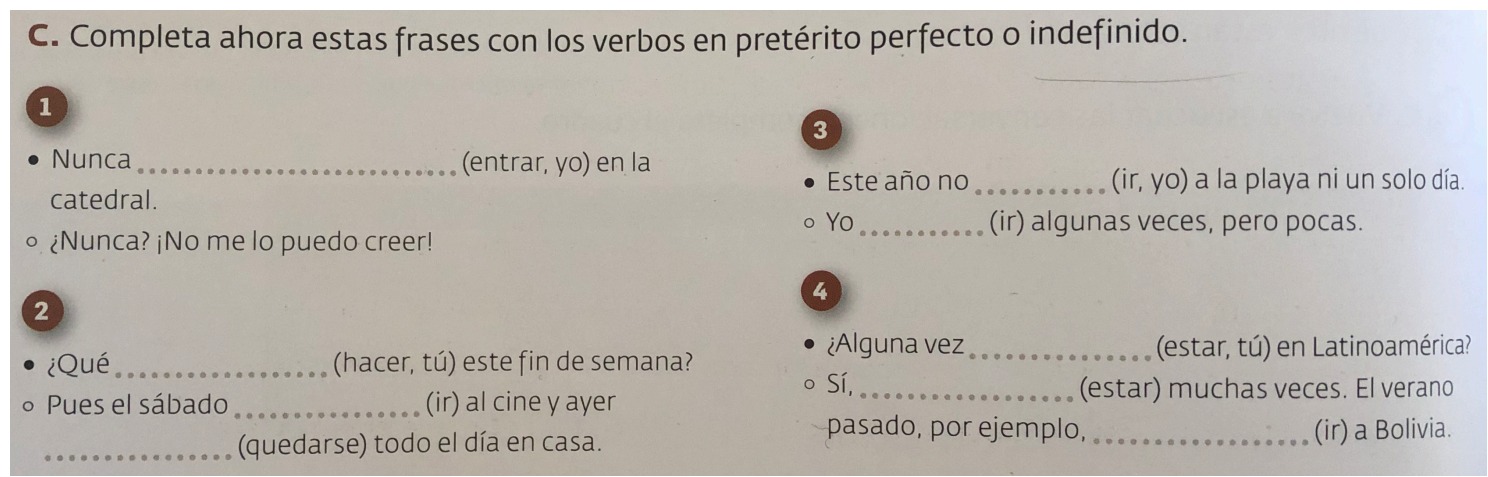

Imagen 2. Actividad de producción de tipo output estructurado. Aula 2 (Difusión)

La gramaticalización (o, mejor dicho, el asentamiento gramatical), en este contexto, se refiere a que en el «output de quienes aprenden una lengua van apareciendo progresivamente los elementos gramaticales sobre la base de los elementos léxicos» (Miquel y Ortega, 2014: 135). Se trata de enseñar a utilizar los elementos gramaticales de forma operativa y comunicativa, progresivamente. Para esto, el planteamiento de estas actividades debe incluir:

a. Información necesaria y organizada «para ofrecer los datos susceptibles de ser utilizados en la producción del texto (dibujos, esquemas, gráficos, textos seleccionados, páginas web, etc.» (Miquel y Ortega, 2014: 136).

b. Un modelo textual, es decir, un tipo de texto que haya que imitar.

c. «Conjunto de recursos lingüísticos mínimos (palabras, frases a medio hacer, etc.) que permitan recomponer y expresar la información ya considerada» (Miquel y Ortega, 2014: 136).

En la siguiente ilustración, extraída del manual Prisma A2, en una edición anterior (año 2007) se ejemplifica este tipo de actividades. El objetivo del ejercicio es practicar conectores temporales de pasado (previamente presentados en cuadros y textos); para ello, se plantea la realización de la biografía de Silvio Rodríguez. Se proporcionan los datos que el estudiante debe incluir en el texto que va a producir, el cual, además, ya está iniciado; se trata de recomponerlo: 


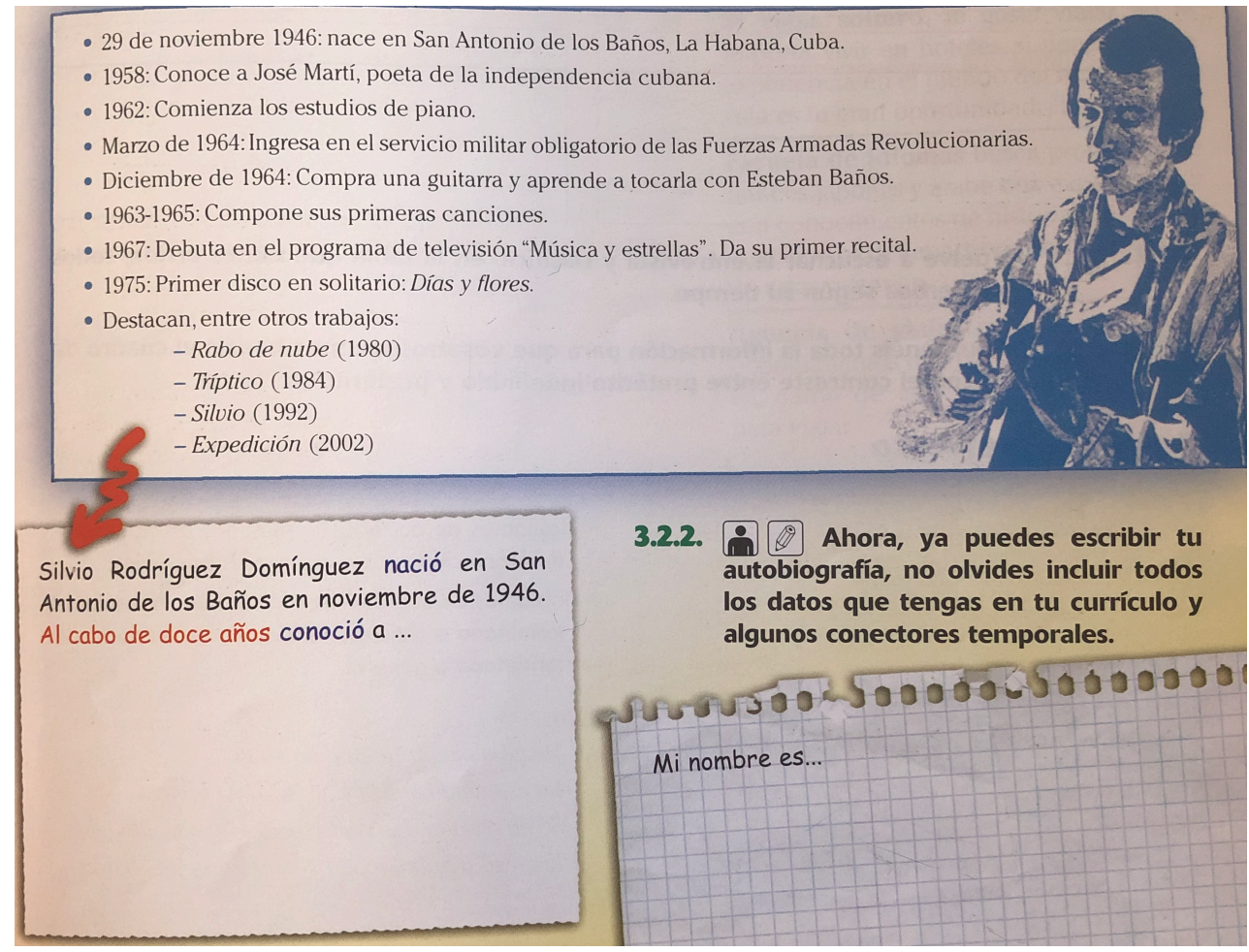

Imagen 3. Actividad de asentamiento gramatical. Prisma A2, 2007 (Edinumen)

\section{Análisis de manuales}

Como ya se ha mencionado previamente, los manuales seleccionados para aplicar el análisis planteado a través de la ficha diseñada son Gramática básica del estudiante de español y Aula 4, de la editorial Difusión; Nuevo Prisma B1, de Edinumen; y ELE Actual $B 1$ de Grupo SM. También se ha mencionado que el nivel de los cuatro manuales seleccionados es B1, por un lado, para acotar el campo de análisis a un solo nivel; por otro, porque en este nivel se trabajan varias de las estructuras gramaticales más investigadas en el ámbito de la GC en ELE. No obstante, el análisis que proponemos podrá llevarse a cabo en manuales de cualquier nivel.

Atendiendo a lo presentado en el epígrafe anterior, la ficha que se ha elaborado está compuesta por tres bloques: el primero de ellos es un apartado identificativo del manual y la edición de este:

\begin{tabular}{|l|l|l|}
\hline 1. Nombre: & \multicolumn{2}{|l|}{} \\
\hline 2. Editorial: & \\
\hline 3. Año de publicación: & \\
\hline 4. Libro del alumno: & \\
\hline 5. Libro de ejercicios: & & \\
\hline 6. Enfoque declarado: & & Sí \\
\hline 7. Declara seguir el MCERL: \\
\hline
\end{tabular}

Tabla 1. Bloque 1: Identificación del manual

La mayoría de los apartados de este primer bloque pueden ser respondidos desde la presentación del propio manual, en la que se indica el enfoque que se ha implantado y si se aplican las directrices del Consejo de Europa (2002). 
El segundo bloque está dedicado a las formas gramaticales y a su tratamiento. En él, se plantean cuestiones como el lugar en el que aparece la explicación gramatical en el manual: antes o después del primer input. Esta cuestión es relevante, pues la GC y la AF buscan que el aprendiente se centre en la forma, su uso y, de esta manera, pueda percibir su significado.

En este segundo bloque, hay preguntas que tratan de detectar si en los manuales se ofrece un único significado o si se ofrecen excepciones de uso (lo cual es contradictorio con la GC). También se busca si la explicación gramatical va acompañada de alguna ilustración que ayude a extender su uso y significado. En este sentido, se han añadido preguntas acerca del cambio de perspectiva que ofrece la elección de una forma gramatical u otra (por ejemplo, las diferencias que se perciben en el uso del pretérito indefinido o del pretérito imperfecto); o cuestiones relativas al input: si en él está destacada la forma por la que se plantea la instrucción, si este input está basado en muestras reales o pretende simularlas y, sobre todo, si es apto para ilustrar el significado de las estructuras:

\begin{tabular}{|c|c|c|}
\hline \multirow{2}{*}{$\begin{array}{l}\text { 8. ¿Cuándo aparece la explicación gramatical: después o antes del } \\
\text { primer input? }\end{array}$} & \multicolumn{2}{|c|}{ Antes } \\
\hline & Sí & No \\
\hline $\begin{array}{l}\text { 10. Las explicaciones del uso, ¿van acompañadas de alguna imagen o } \\
\text { ilustración? }\end{array}$ & Sí & No \\
\hline $\begin{array}{l}\text { 11. ¿Las imágenes procuran explicar el significado y/o el uso de } \\
\text { esta o simplemente son decorativas? }\end{array}$ & \multicolumn{2}{|c|}{ Decoran } \\
\hline \multirow{4}{*}{ 12. La explicación gramatical que se ofrece implica: } & \multicolumn{2}{|c|}{ Varias normas y excepciones de uso } \\
\hline & \multicolumn{2}{|c|}{ Una norma y excepciones de uso } \\
\hline & \multicolumn{2}{|c|}{$\begin{array}{l}\text { No se incide tanto en la norma como er } \\
\text { sus usos }\end{array}$} \\
\hline & \multicolumn{2}{|c|}{$\begin{array}{l}\text { Una única norma explicada para todos } \\
\text { los posibles contextos de uso } \\
\text { (significado operativo) }\end{array}$} \\
\hline $\begin{array}{l}\text { 13. Cuando se presentan dos formas que contrastan, ¿se incide en el cambio de } \\
\text { perspectiva? }\end{array}$ & Sí & No \\
\hline \multicolumn{2}{|l|}{$\begin{array}{l}\text { 14. ¿Las formas gramaticales que se trabajan, aparecen señaladas a través de } \\
\text { algún recurso tipográfico (negrita, cursiva, mayúsculas, un color } \\
\text { diferente...)? }\end{array}$} & No \\
\hline $\begin{array}{l}\text { 15. ¿El input que se presenta se basa en muestras reales de habla, aunque estas } \\
\text { estén adaptadas al nivel y/u objetivos de la instrucción? }\end{array}$ & Sí & No \\
\hline $\begin{array}{l}\text { 16. ¿El input que se presenta está enfocado a explicar el uso de las formas } \\
\text { gramaticales y su significado? }\end{array}$ & $\mathrm{S}$ & No \\
\hline
\end{tabular}

Tabla 2. Bloque 2: Presentación de la gramática

El tercer y último bloque de la ficha metodológica de análisis se centra en el tipo o tipos de actividades que se plantean y cómo vienen presentadas. Así, se busca que los ejercicios, tanto de producción como de comprensión o interpretación, pongan el foco en las formas gramaticales. Por todo ello, en los manuales que recurran a la GC se esperan actividades de práctica controlada (que buscan que el estudiante utilice los recursos gramaticales trabajados) en las que se incida en el uso de las formas en los ejercicios. En este sentido, se busca una progresión. También se analizará si el input de las actividades es estructurado (al igual que el output), si las actividades buscan que el discente adquiera conciencia de qué son las formas gramaticales, para qué son y cuál es su significado (y si 
lo hace de forma inductiva o deductiva); $\mathrm{y}$, por último, si las actividades son de gramaticalización:

\begin{tabular}{|c|c|c|c|}
\hline $\begin{array}{l}\text { 17. ¿Las actividades que se proponen son de práctica controlada } \\
\text { o de práctica libre? }\end{array}$ & Controlada & & ibre \\
\hline \multicolumn{2}{|c|}{$\begin{array}{l}\text { 18. ¿La progresión de las actividades empieza enfocando la importancia en el } \\
\text { contenido o en el significado de las formas y, poco a poco, van incidiendo } \\
\text { más en la construcción de las formas? }\end{array}$} & Sí & No \\
\hline \multicolumn{2}{|l|}{ 19. ¿Las actividades que se proponen son de input estructurado? } & Sí & No \\
\hline \multicolumn{2}{|c|}{ 20. ¿Las actividades que se proponen son de toma de conciencia gramatical? } & Sí & No \\
\hline 21. Si la respuesta anterior es sí, ¿de qué tipo? & Deductivo & \multicolumn{2}{|c|}{ Inductivo } \\
\hline \multicolumn{2}{|l|}{ 22. ¿Las actividades que se proponen son de output estructurado? } & Sí & No \\
\hline \multicolumn{2}{|l|}{ 23. ¿Las actividades que se proponen son de gramaticalización? } & Sí & No \\
\hline
\end{tabular}

Tabla 3. Bloque 3: Actividades

\subsection{Gramática básica del estudiante de español}

La edición analizada de este manual es del año 2015, consta de un solo volumen y el enfoque metodológico que se declara en su presentación es, precisamente, el de la GC y operativa. Es importante destacar que este método no puede compararse con el resto por los siguientes motivos: en primer lugar, es un manual de autoaprendizaje, no pensado para su aplicación didáctica en el aula (el resto sí lo son); por otro lado, engloba los tres primeros niveles del MCERL, de A1 a B1 (los otros tres manuales se corresponden con B1). Además, como ya se ha indicado, es el único manual que afirma recurrir a la GC tanto en sus explicaciones gramaticales como en sus actividades. Sin embargo, hemos insistido en incluirlo en el análisis por considerar que su metodología didáctica es de las que mejor se ajusta a los planteamientos de la GC y, por tanto, puede servir para ilustrar el análisis y la ficha metodológica.

\begin{tabular}{|l|l|l|}
\hline 1. Nombre: & Gramática básica del estudiante de español \\
\hline 2. Editorial: & Difusión & \\
\hline 3. Año de publicación: & 2015 \\
\hline 4. Libro del alumno: & - \\
\hline 5. Libro de ejercicios: & - & \\
\hline 6. Enfoque declarado: & Gramática cognitiva / Gramática operativa & Sí \\
\hline 7. Declara seguir el MCERL:
\end{tabular}

Tabla 4. Bloque 1: Identificación del manual de Gramática básica del estudiante de español (Difusión)

En cuanto a la presentación de las estructuras gramaticales, se le da prioridad a su significado y no tanto a las cuestiones formales. Como se aprecia en las siguientes imágenes, se ofrece, en primer lugar, un pequeño esquema de las terminaciones del presente de subjuntivo, pero en las posteriores explicaciones gramaticales se trata de desarrollar el funcionamiento de esta forma verbal. Además, recurre al uso de ilustraciones para explicar el significado de este tiempo: 


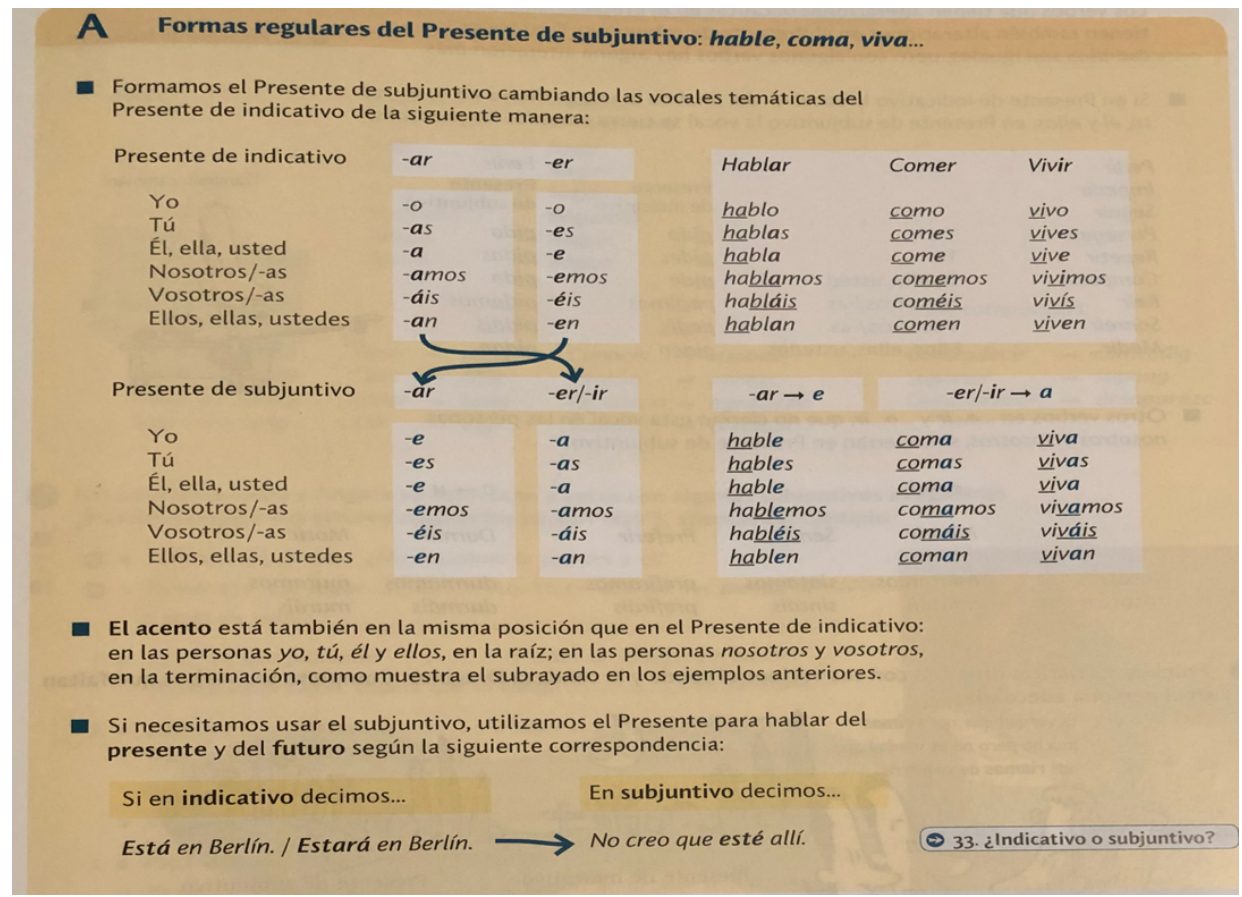

Imagen 4. Formas del presente de indicativo y del presente de subjuntivo. GBEE (Difusión)

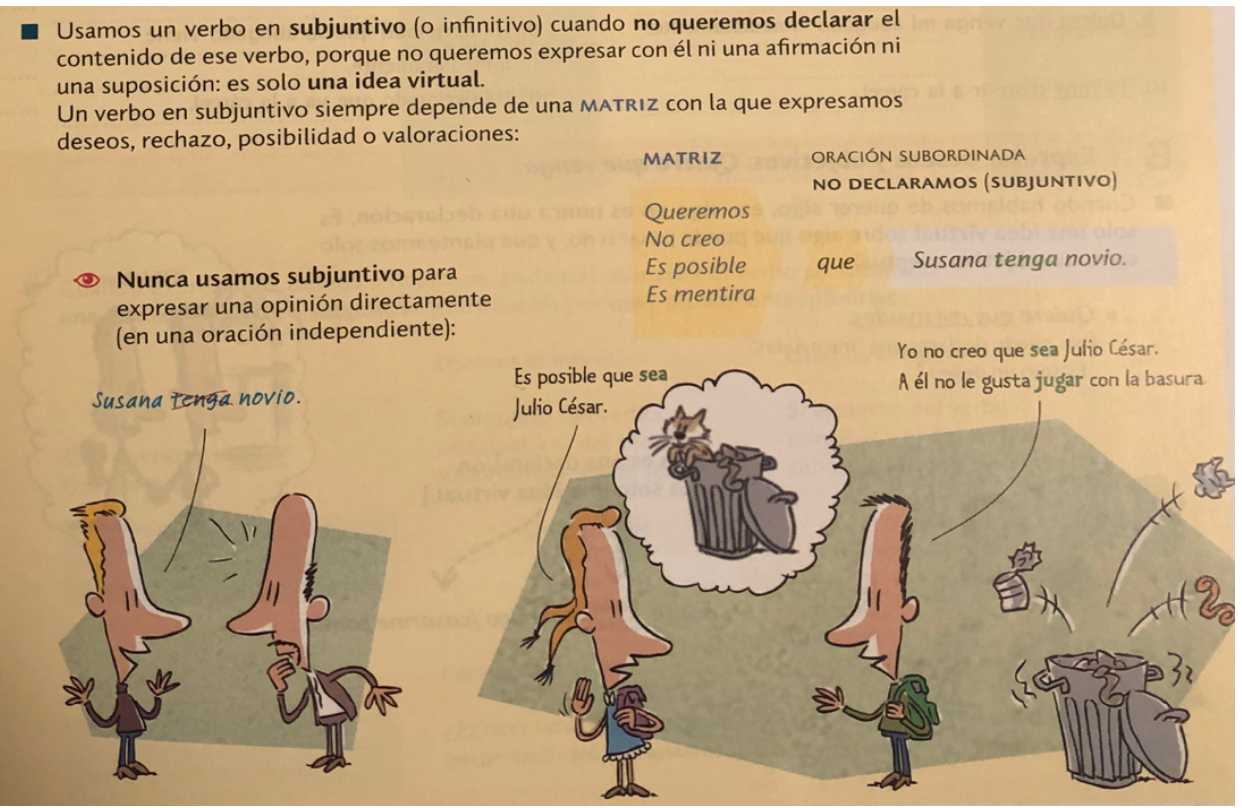

Imagen 5. Explicación del significado operativo del presente de subjuntivo. GBEE (Difusión)

Además, se trabaja una única forma a la que se le trata de asignar un único sentido. Es lo que Ruiz Campillo denomina el significado operativo de las formas gramaticales (2005, 2007a).

Por otro lado, el input sí que aparece marcado (podemos ver el verbo destacado, marcado en color verde), como podemos ver en la imagen 3; además, es un input estructurado, ya que los ejemplos de uso, aunque resultan verosímiles, están presentados de tal manera que la interpretación del significado de las formas gramaticales por parte del aprendiente 
sea el adecuado en cada caso. Además, los ejemplos colaboran en la buena interpretación de este significado operativo.

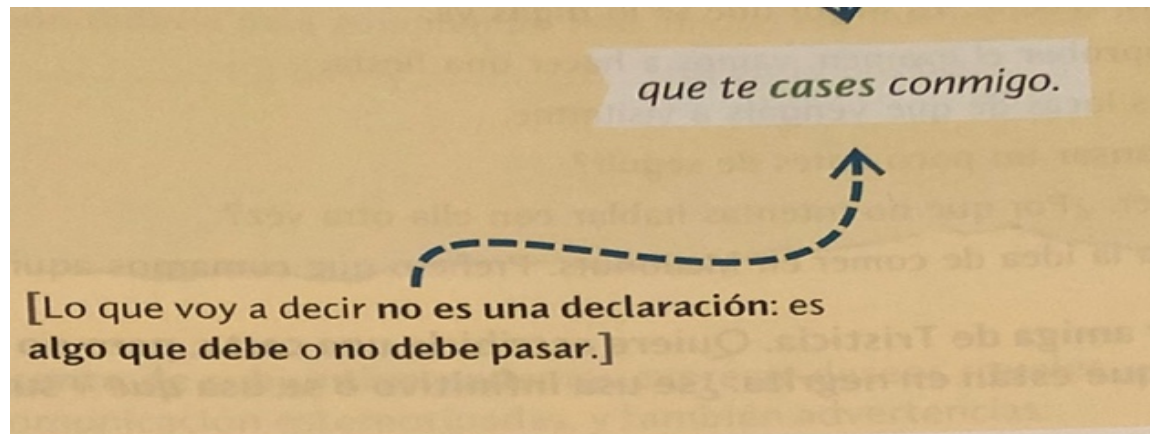

Imagen 6. Ejemplo de input estructurado. Gramática básica del estudiante de español (Difusión)

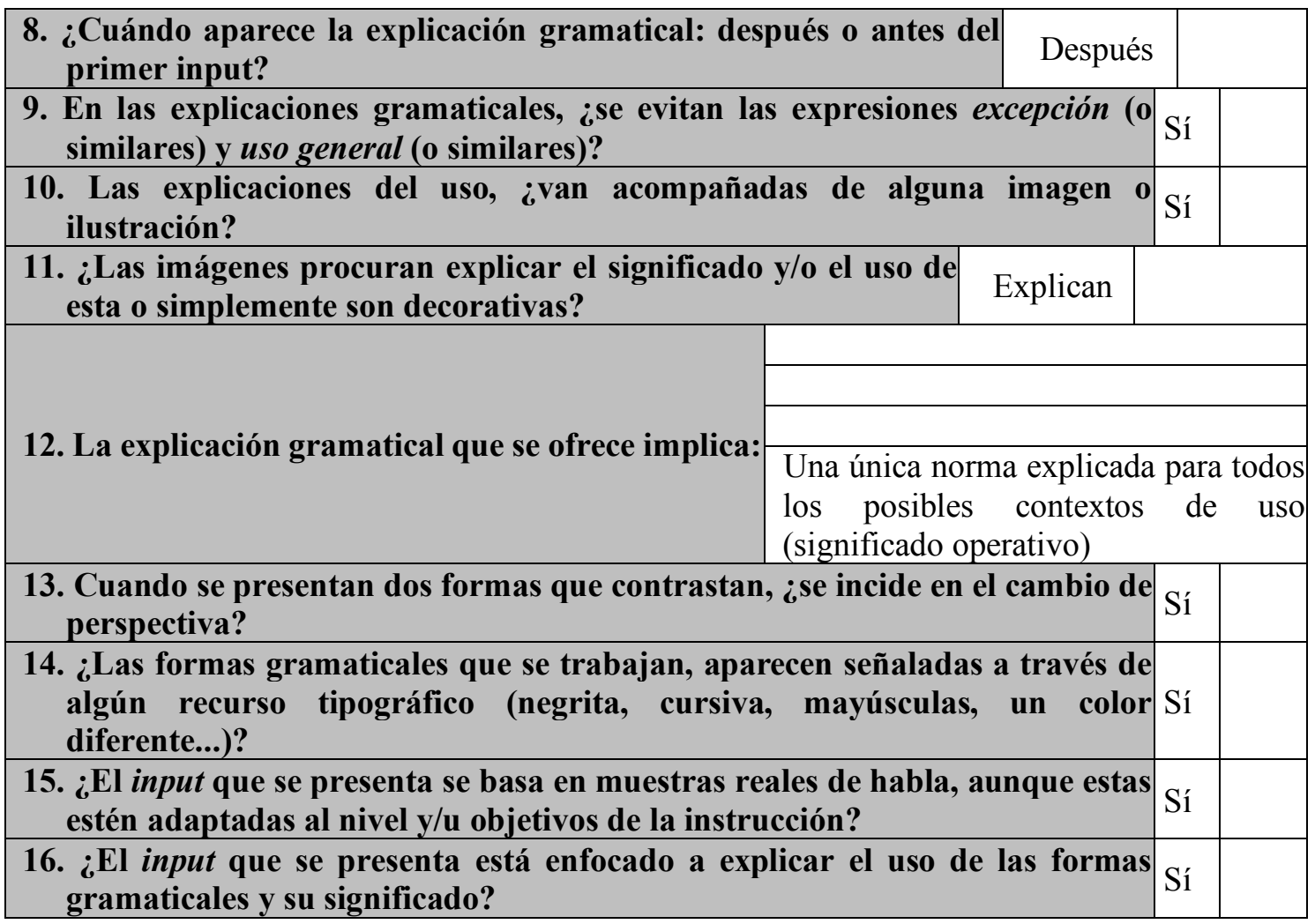

Tabla 5. Bloque 2: Presentación de la gramática en Gramática básica del estudiante de español

$$
\text { (Difusión) }
$$

En cuanto a las actividades, todas las que componen cada uno de los temas de este manual son de práctica controlada. Lo primero que se busca con ellas es la interpretación del significado y posteriormente se van trabajando las estructuras formales, como se ilustra en las imágenes 4 y 5 . 


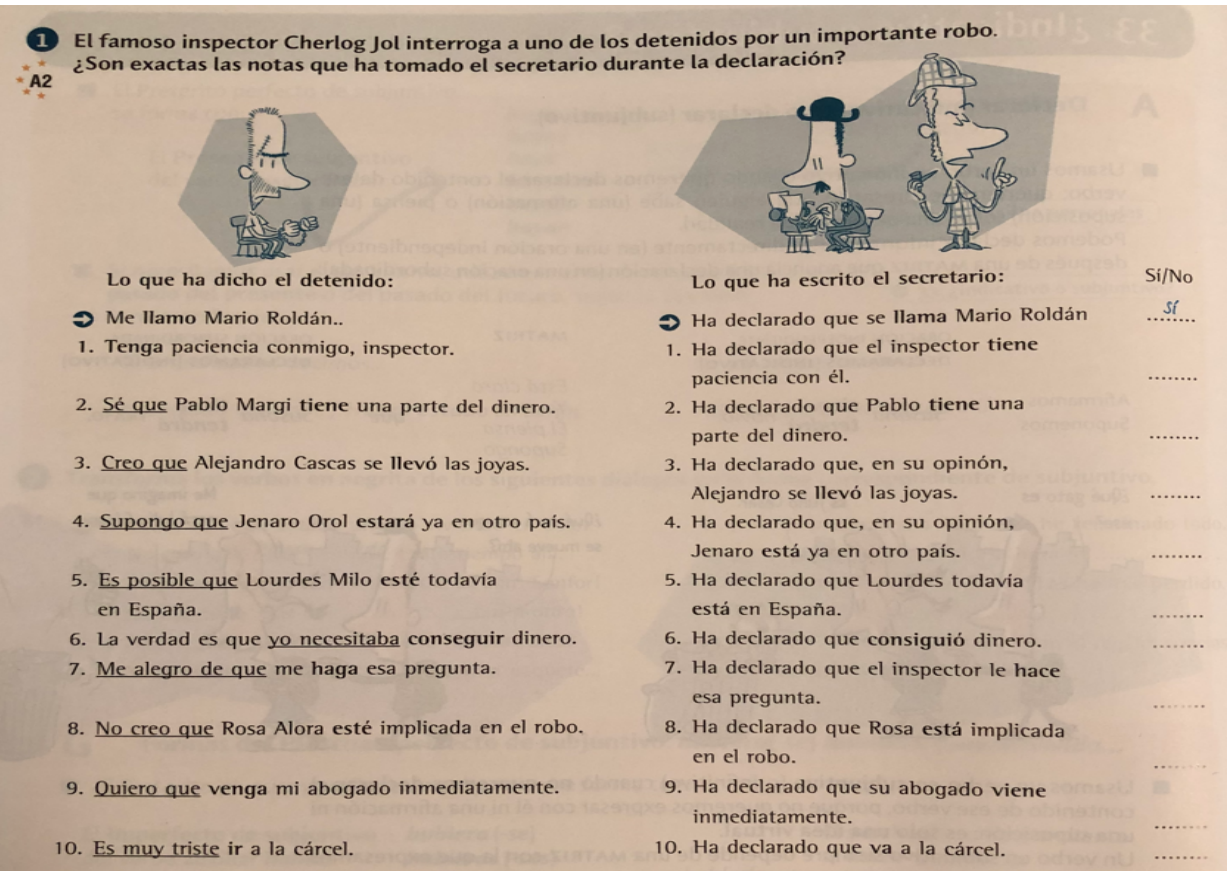

Imagen 7. Actividad de práctica controlada para el presente de subjuntivo. Gramática básica del estudiante de español (Difusión)

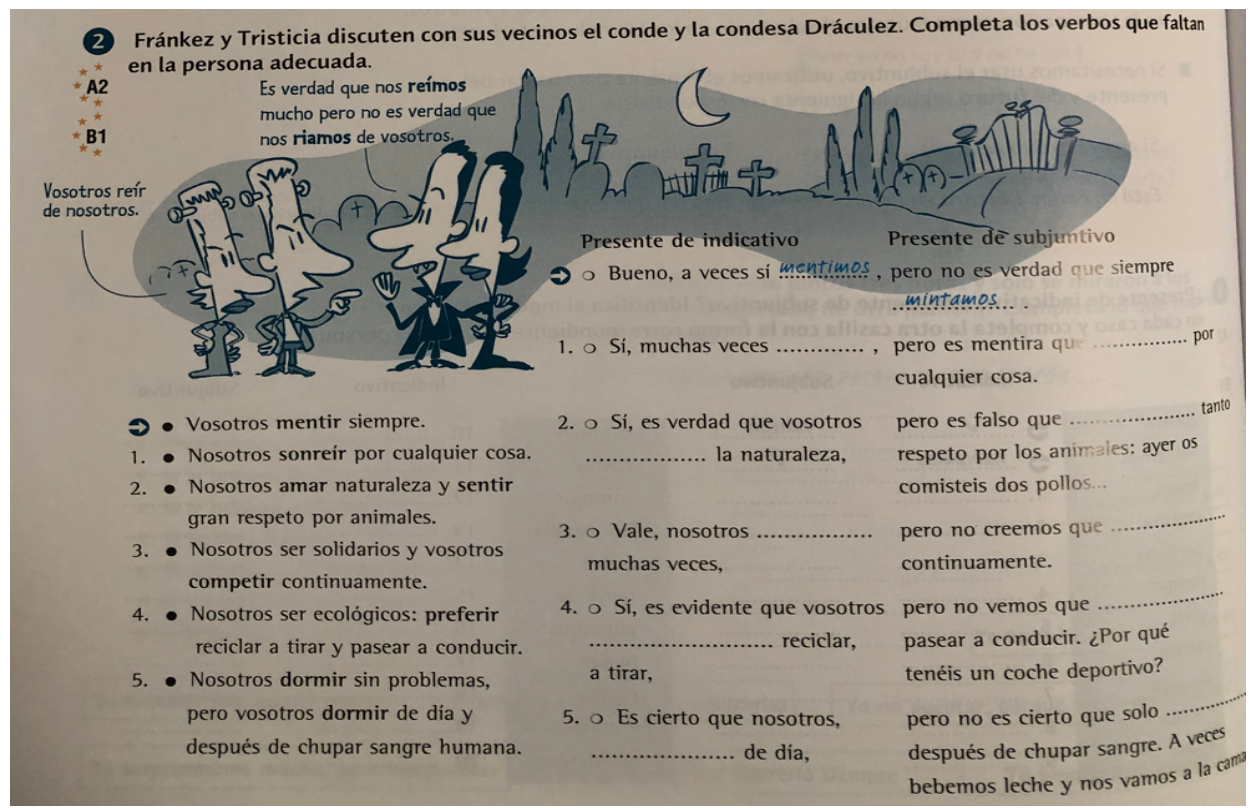

Imagen 8. Actividad de output estructurado para el presente de subjuntivo. Gramática básica del estudiante de español (Difusión)

En la imagen 4 se presenta una actividad de conciencia gramatical planteada desde un punto de vista deductivo. En la imagen 5 se presenta otra en la que se trabaja la forma del presente de indicativo y subjuntivo una vez ya se ha reforzado el significado de ambas, y el output es estructurado, ya que la respuesta que los estudiantes deben producir está muy orientada en el planteamiento de la actividad. 


\begin{tabular}{|l|l|l|}
\hline $\begin{array}{l}\text { 17. ¿Las actividades que se proponen son de práctica controlada } \\
\text { o de práctica libre? }\end{array}$ & \\
\hline $\begin{array}{l}\text { 18. ¿La progresión de las actividades empieza enfocando la importancia en el } \\
\text { contenido o en el significado de las formas y, poco a poco, van incidiendo } \\
\text { más en la construcción de las formas? }\end{array}$ & No \\
\hline \begin{tabular}{l|l|l|} 
19. ¿Las actividades que se proponen son de input estructurado? & Sí & \\
\hline 20. ¿Las actividades que se proponen son de toma de conciencia gramatical? & Sí & \\
\hline 21. Si la respuesta anterior es sí, ¿de qué tipo? & \multicolumn{2}{|c|}{} \\
\hline 22. ¿Las actividades que se proponen son de output estructurado? & Sí & \\
\hline 23. ¿Las actividades que se proponen son de gramaticalización? & No \\
\hline
\end{tabular}
\end{tabular}

Tabla 6. Bloque 3: Actividades en Gramática básica del estudiante de español (Difusión)

\subsection{Aula 4}

La colección Aula de la editorial Difusión está compuesta por seis volúmenes. El que hemos seleccionado (el volumen 4) se corresponde con el nivel B1.2. En este se tratan varios usos del presente de subjuntivo y se hace un breve repaso del contraste de pasados de indicativo, es por ello que ha sido seleccionado para este estudio. La edición con la que se ha trabajado es del año 2014.

El Aula 4 recoge en un solo libro las explicaciones gramaticales y las actividades; declara aplicar una metodología comunicativa y seguir las pautas marcadas por el Consejo de Europa (2002).

\begin{tabular}{|l|l|l|l|}
\hline 1. Nombre: & Aula 4 & \\
\hline 2. Editorial: & Difusión & \\
\hline 3. Año de publicación: & 2014 \\
\hline 4. Libro del alumno: & - \\
\hline 5. Libro de ejercicios: & - & \\
\hline 6. Enfoque declarado: & Comunicativo & Sí & \\
\hline 7. Declara seguir el MCERL:
\end{tabular}

Tabla 7. Bloque 1: Identificación del manual de Aula 4 (Difusión)

En cuanto a las explicaciones gramaticales, se otorga más prioridad al sentido de las estructuras y no tanto a su formación, aunque esta también es trabajada. Es importante destacar que no se habla en ningún momento de excepciones de uso, lo cual es una de las principales pautas de la GC. Al contrario de lo que sucede en el manual analizado previamente, no aparecen imágenes acompañando las explicaciones gramaticales en todos los casos, pero sí que se incide en la perspectiva, como puede verse en la imagen 6: 


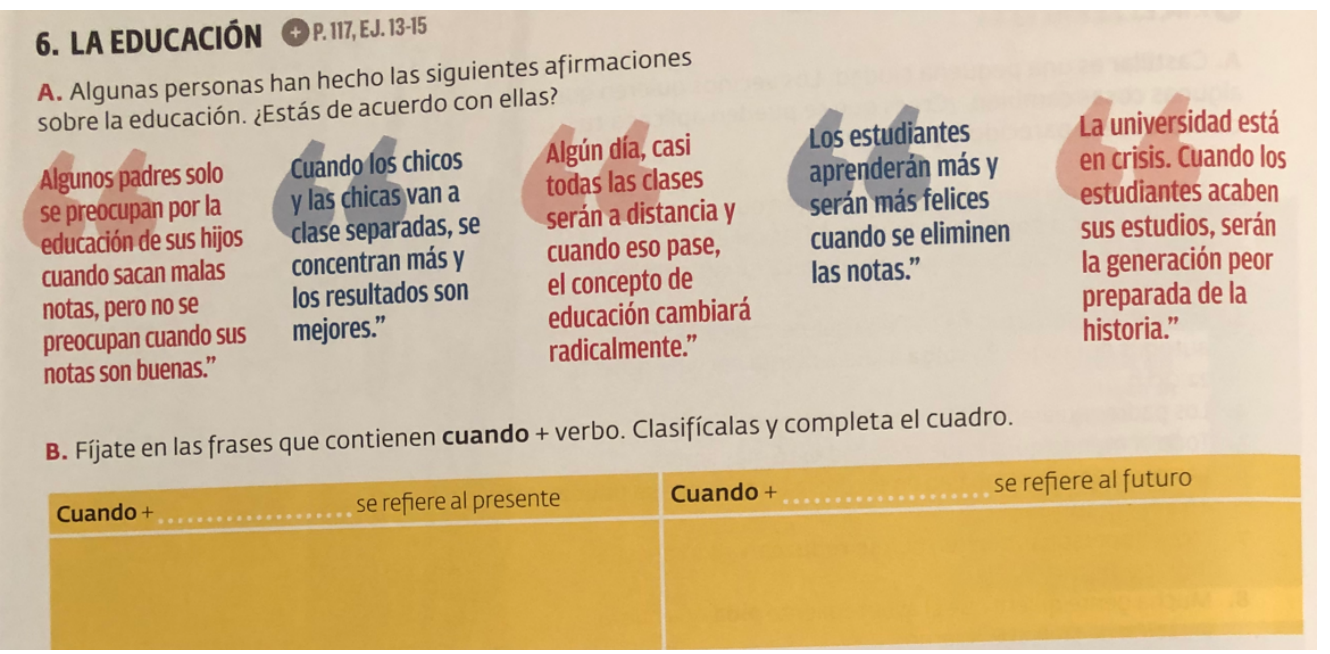

Imagen 9. Ejemplo del enfoque inductivo de los usos de cuando en Aula 4 (Difusión)

En la imagen 6 podemos apreciar cómo se busca que, a partir de los ejemplos, el aprendiente intuya cuándo se utiliza el indicativo y cuándo, el subjuntivo, por lo que se está llevando a cabo un método inductivo de enseñanza de la gramática, característico del enfoque cognitivo. Además, el input que se ofrece en estas explicaciones suele aparecer marcado, es estructurado y su objetivo es explicar el significado de la forma gramatical trabajada, como puede verse en la imagen 7 :

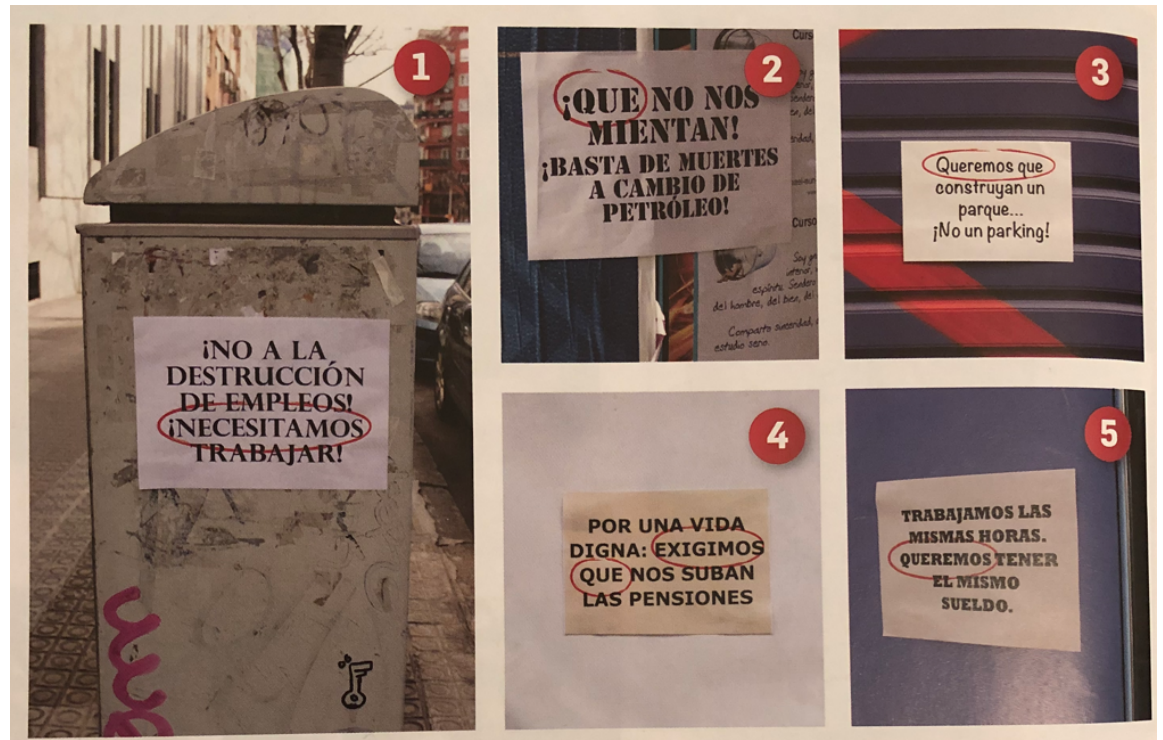

Imagen 10. Ejemplo de input en el manual Aula 4 (Difusión) 


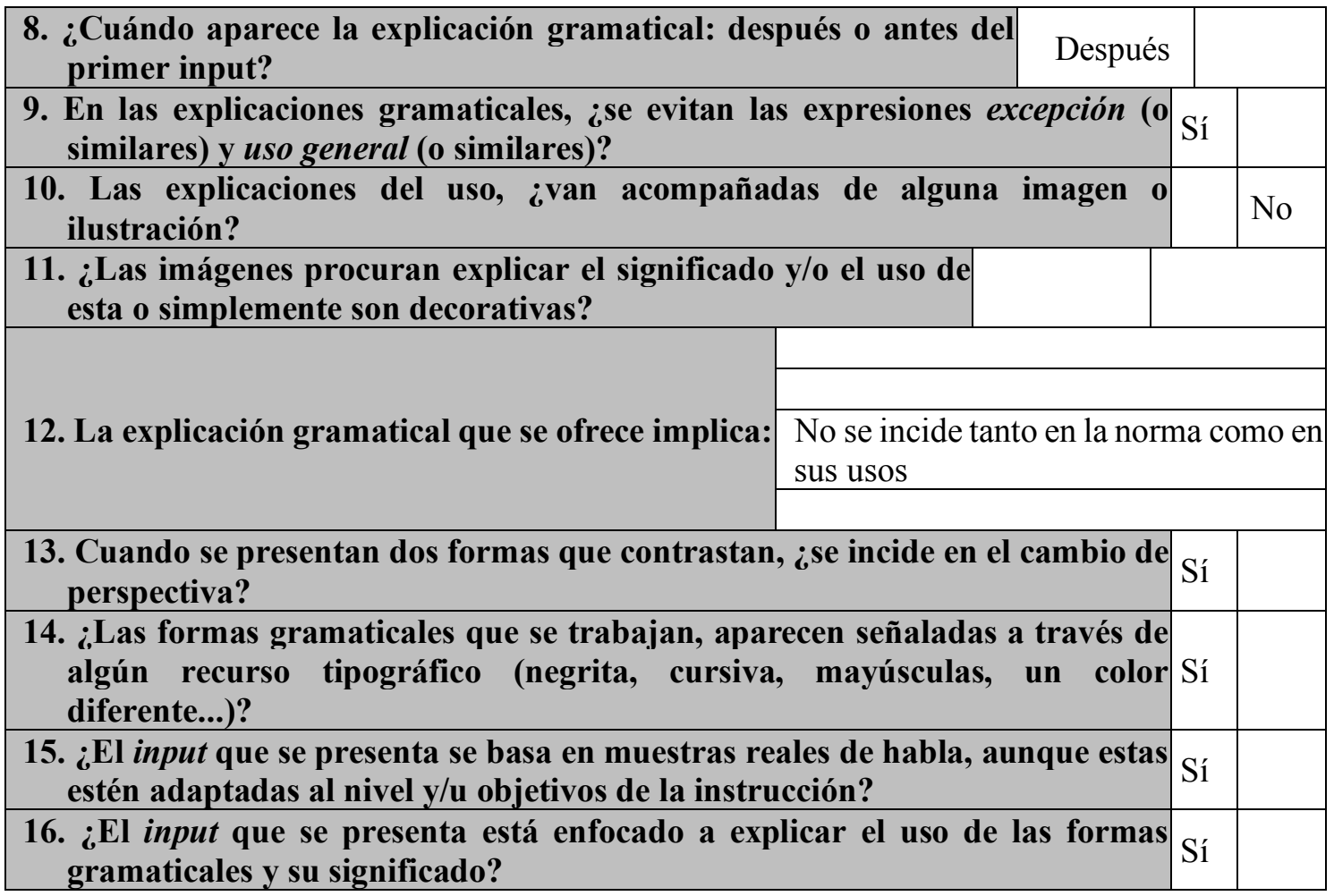

Tabla 8. Bloque 2: Presentación de la gramática en Aula 4 (Difusión)

Las actividades de este manual también son de práctica controlada y se pone el foco en el significado de las formas, aunque también se trabaja la producción de estas:

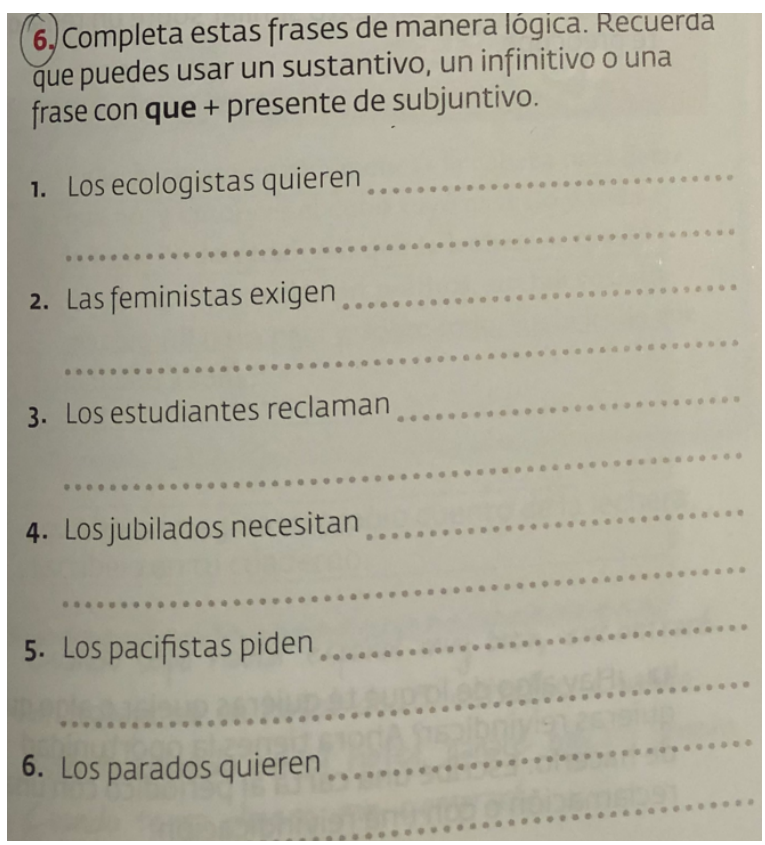

Imagen 11. Actividad de práctica controlado en Aula 4 (Difusión)

Además, también son frecuentes las actividades de toma de conciencia gramatical, basadas en un enfoque inductivo (imagen 9); y de output estructurado, así como de gramaticalización, en las que el estudiante tiene que demostrar que ha asentado la forma aprendida en una producción (imagen 10): 


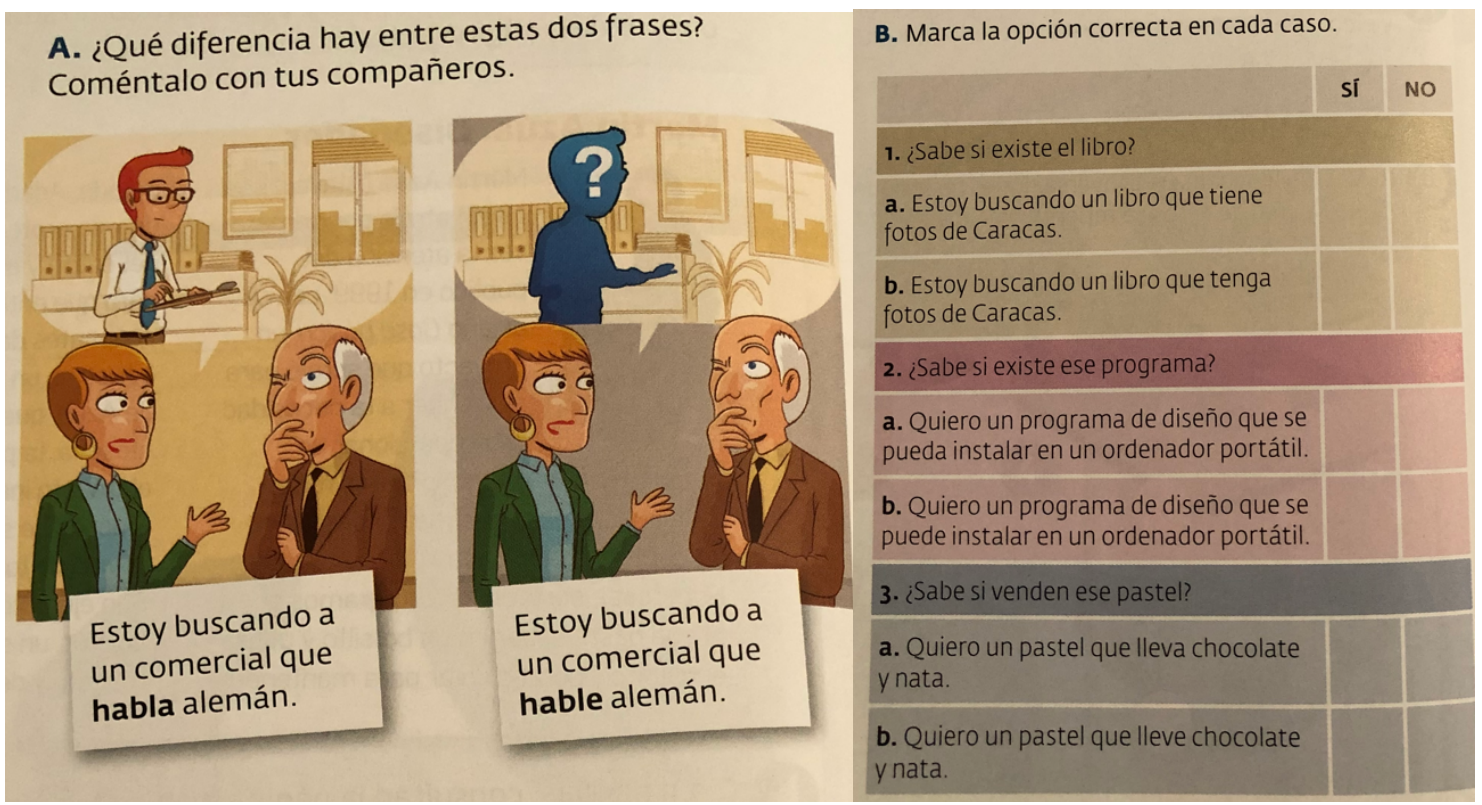

Imagen 12. Actividad de toma de conciencia gramátical, enfoque inductivo en Aula 4 (Difusión)

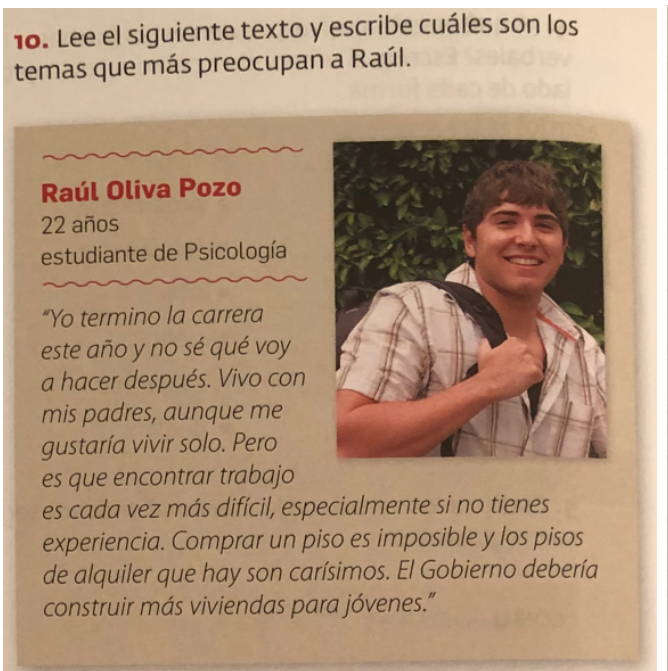
11. ¿Y a ti? Escribe un texto similar sobre un tema que te preocupe.

Imagen 13. Actividad de gramaticalización en Aula 4 (Difusión)

\begin{tabular}{|c|c|c|}
\hline $\begin{array}{l}\text { 17. ¿Las actividades que se proponen son de práctica controlada } \\
\text { o de práctica libre? }\end{array}$ & & \\
\hline $\begin{array}{l}\text { 18. ¿La progresión de las actividades empieza enfocando la importancia en el } \\
\text { contenido o en el significado de las formas y, poco a poco, van incidiendo } \\
\text { más en la construcción de las formas? }\end{array}$ & Sí & \\
\hline 19. ¿Las actividades que se proponen son de input estructurado? & Sí & \\
\hline 20. ¿Las actividades que se proponen son de toma de conciencia gramatical? & Sí & \\
\hline 21. Si la respuesta anterior es sí, ¿de qué tipo? & \multicolumn{2}{|c|}{ Inductivo } \\
\hline 22. $i$ Las actividades que se proponen son de $o u$ & & \\
\hline 23. ¿Las actividade & Sí & \\
\hline
\end{tabular}

Tabla 9. Bloque 3: Actividades en Aula 4 (Difusión) 


\subsection{Nuevo Prisma B1}

El manual Nuevo Prisma B1 de la editorial Edinumen se compone de un libro del alumno y de otro de ejercicios. La edición que se ha analizado es del año 2015 y en sus primeras páginas se declara un enfoque comunicativo, orientado a la acción. Sigue las directrices marcadas por el Consejo de Europa (2002).

\begin{tabular}{|l|l|l|}
\hline 1. Nombre: & Nuevo Prisma B1 \\
\hline 2. Editorial: & Edinumen \\
\hline 3. Año de publicación: & $\mathbf{2 0 1 5}$ \\
\hline 4. Libro del alumno: & Sí \\
\hline 5. Libro de ejercicios: & Sí & Sí \\
\hline 6. Enfoque declarado: & Comunicativo orientado a la acción \\
\hline 7. Declara seguir el MCERL:
\end{tabular}

Tabla 10. Bloque 1: Identificación del manual de Nuevo Prisma B1 (Edinumen)

Las explicaciones gramaticales aparecen después del primer input de la forma gramatical centro de la instrucción. En estas explicaciones, se evita el uso de las palabras excepción y uso general o similares. Sin embargo, las explicaciones no van acompañadas de imágenes que faciliten la comprensión del significado o uso de la forma gramatical.

El input sí que aparece marcado, es estructurado (al igual que en el resto de manuales) y su objetivo es ayudar a ilustrar el uso de las formas trabajadas, como puede verse en la imagen 11, donde se trabajan algunos conectores de causa:

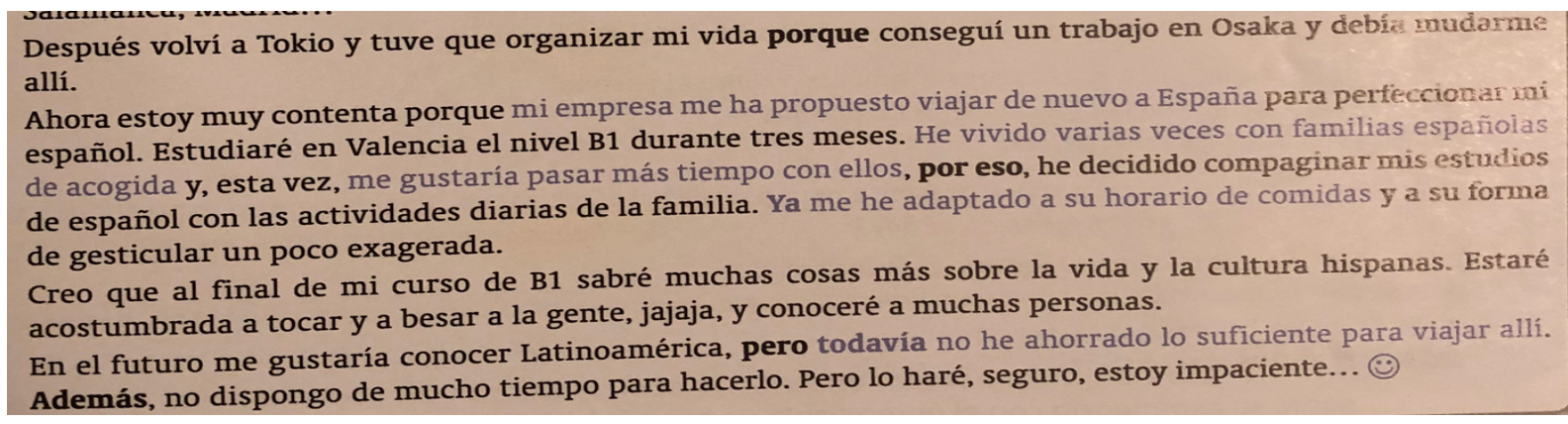

Imagen 14. Fragmento de un texto del manual Nuevo Prisma B1 (Edinumen) 


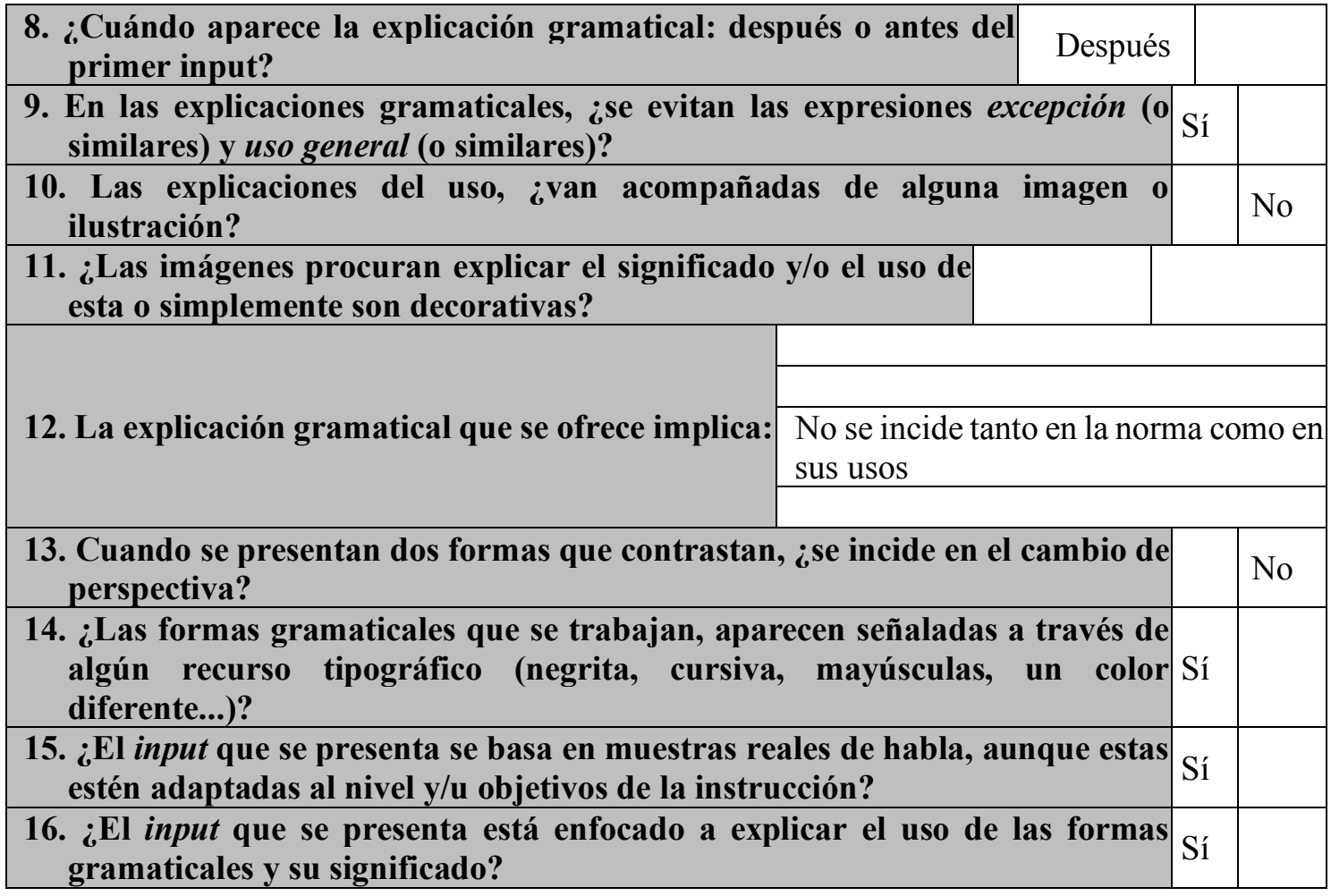

Tabla 11. Bloque 2: Presentación de la gramática en Nuevo Prisma B1 (Edinumen)

Las actividades que se presentan, al igual que en los análisis previos, son mayoritariamente de práctica controlada. Sin embargo, se incide en la construcción de las formas a lo largo de las primeras actividades, antes de pasar a trabajar los usos o el significado de estas, lo que se lleva a cabo en las finales. El input también es estructurado, como vemos en la imagen 12, aparecen marcadas las estructuras que son trabajadas, lo que facilita la instrucción. Por último, se presentan también actividades de conciencia gramatical basadas en un enfoque inductivo, como se ilustra en la imagen 13.

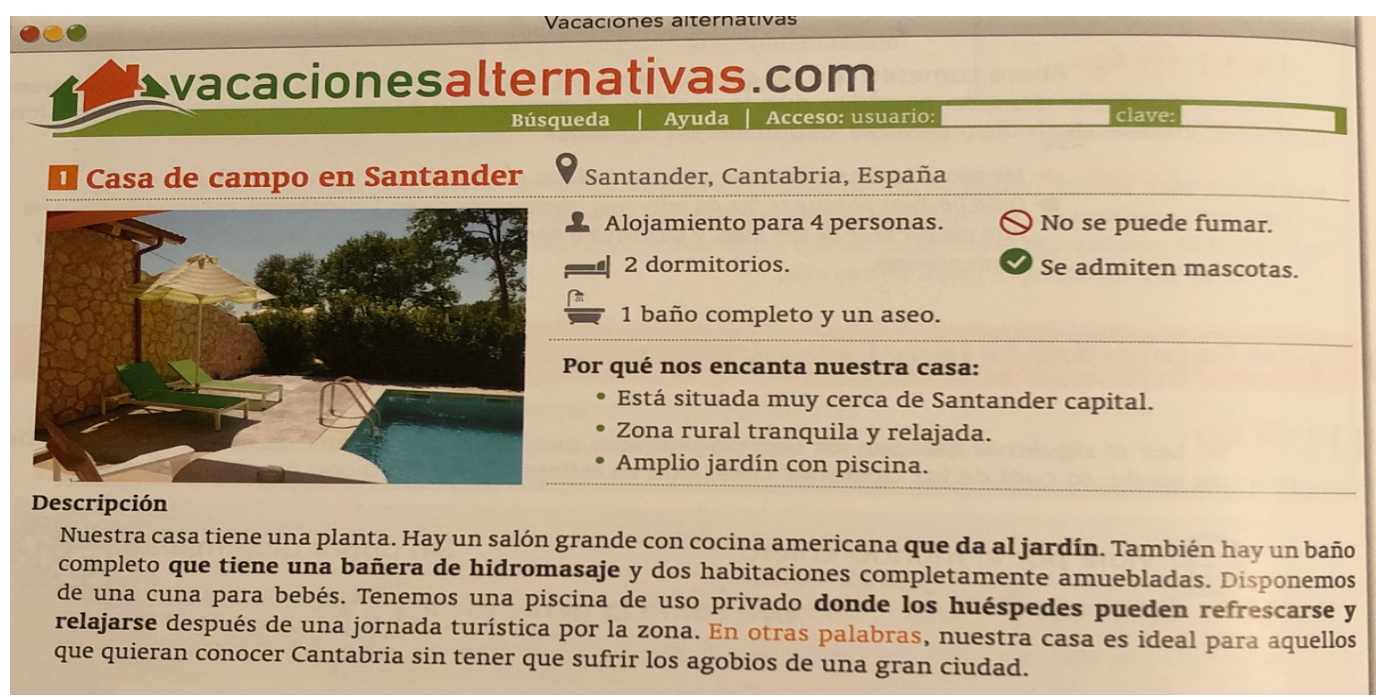

Imagen 15. Actividad con input estructurado. Nuevo Prisma B1 (Edinumen) 


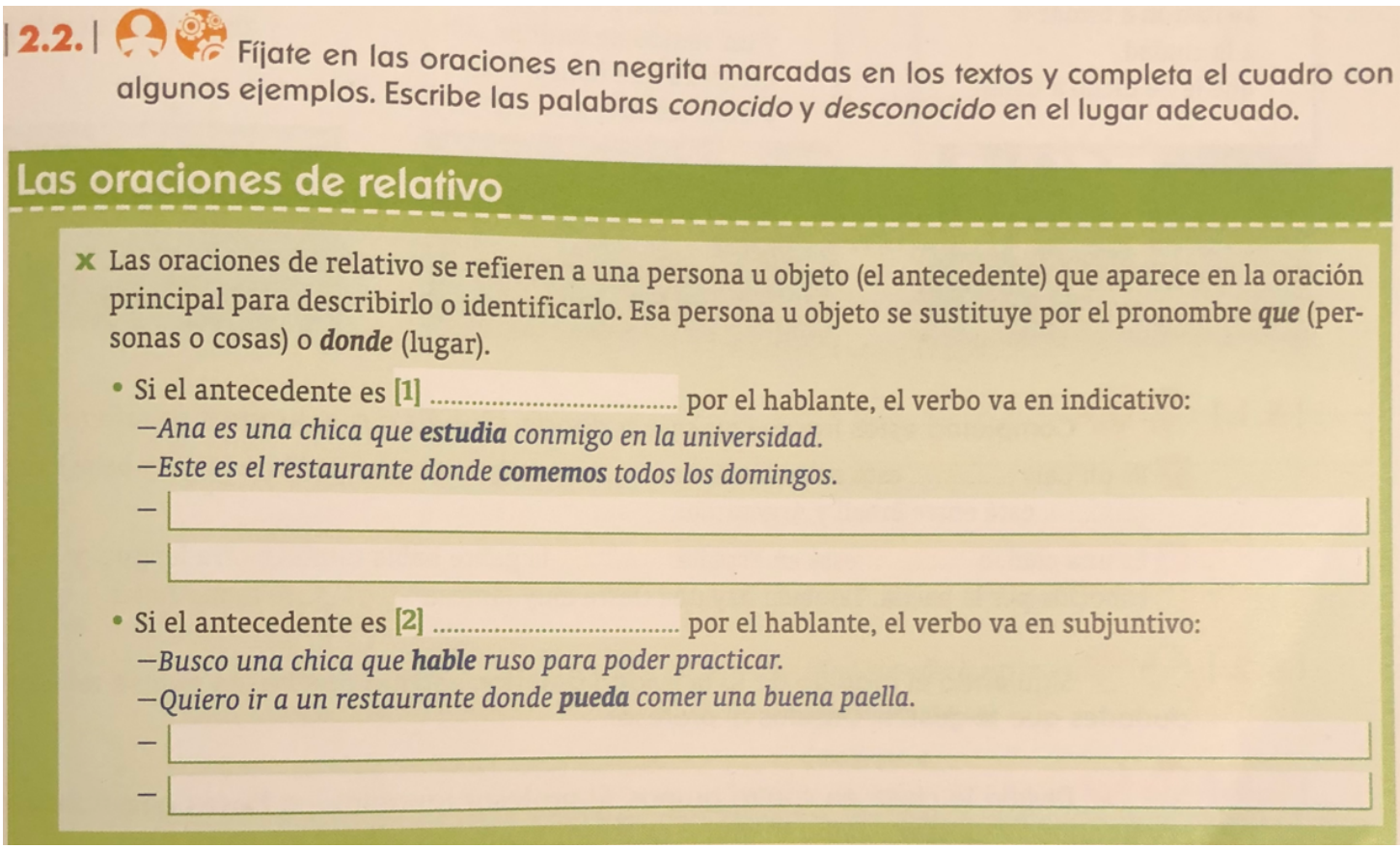

Imagen 16. Actividad de conciencia gramatical, enfoque inductivo, en Nuevo Prisma B1 (Edinumen)

En este manual no se han encontrado actividades de gramaticalización ni de output estructurado.

\begin{tabular}{|c|c|c|}
\hline $\begin{array}{l}\text { 17. ¿Las actividades que se proponen son de práctica controlada } \\
\text { o de práctica libre? }\end{array}$ & & \\
\hline $\begin{array}{l}\text { 18. ¿La progresión de las actividades empieza enfocando la importancia en el } \\
\text { contenido o en el significado de las formas y, poco a poco, van incidiendo } \\
\text { más en la construcción de las formas? }\end{array}$ & & No \\
\hline 19. ¿Las actividades que se proponen son de input estructurado? & Sí & \\
\hline 20. ¿Las actividades que se proponen son de toma de conciencia gramatical? & & \\
\hline 21. Si la respuesta anterior es sí, ¿de qué tipo? & \multicolumn{2}{|c|}{ Inductivo } \\
\hline 22. ¿Las actividades & & \\
\hline 23. ¿Las actividades qu & & No \\
\hline
\end{tabular}

Tabla 12. Bloque 3: Actividades en Nuevo Prisma B1 (Edinumen)

\subsection{ELE Actual B1}

El último método analizado es de la editorial S\&M y fue publicado en el año 2012. También se compone de un manual del alumno y de otro de actividades. El enfoque metodológico declarado es el comunicativo y sigue las directrices del MCERL.

\begin{tabular}{|l|l|l|l|}
\hline 1. Nombre: & ELE Actual B1 \\
\hline 2. Editorial: & S\&M & \multicolumn{2}{l|}{} \\
\hline 3. Año de publicación: & $\mathbf{2 0 1 2}$ \\
\hline 4. Libro del alumno: & Sí \\
\hline 5. Libro de ejercicios: & Sí & Sí \\
\hline 6. Enfoque declarado: & Comunicativo & \\
\hline 7. Declara seguir el MCERL:
\end{tabular}

Tabla 13. Bloque 1: Identificación del manual de ELE Actual B1 (S\&M) 
Las explicaciones gramaticales de este manual están elaboradas atendiendo a la metodología de la GC: se pasa de la forma al significado, no se habla de excepciones, se presentan los usos (no las normas) y se incide en la perspectiva, aunque todo esto se lleva a cabo en el apéndice gramatical, es decir, el alumno tiene que acudir a las últimas páginas del libro para llegar a esta información:

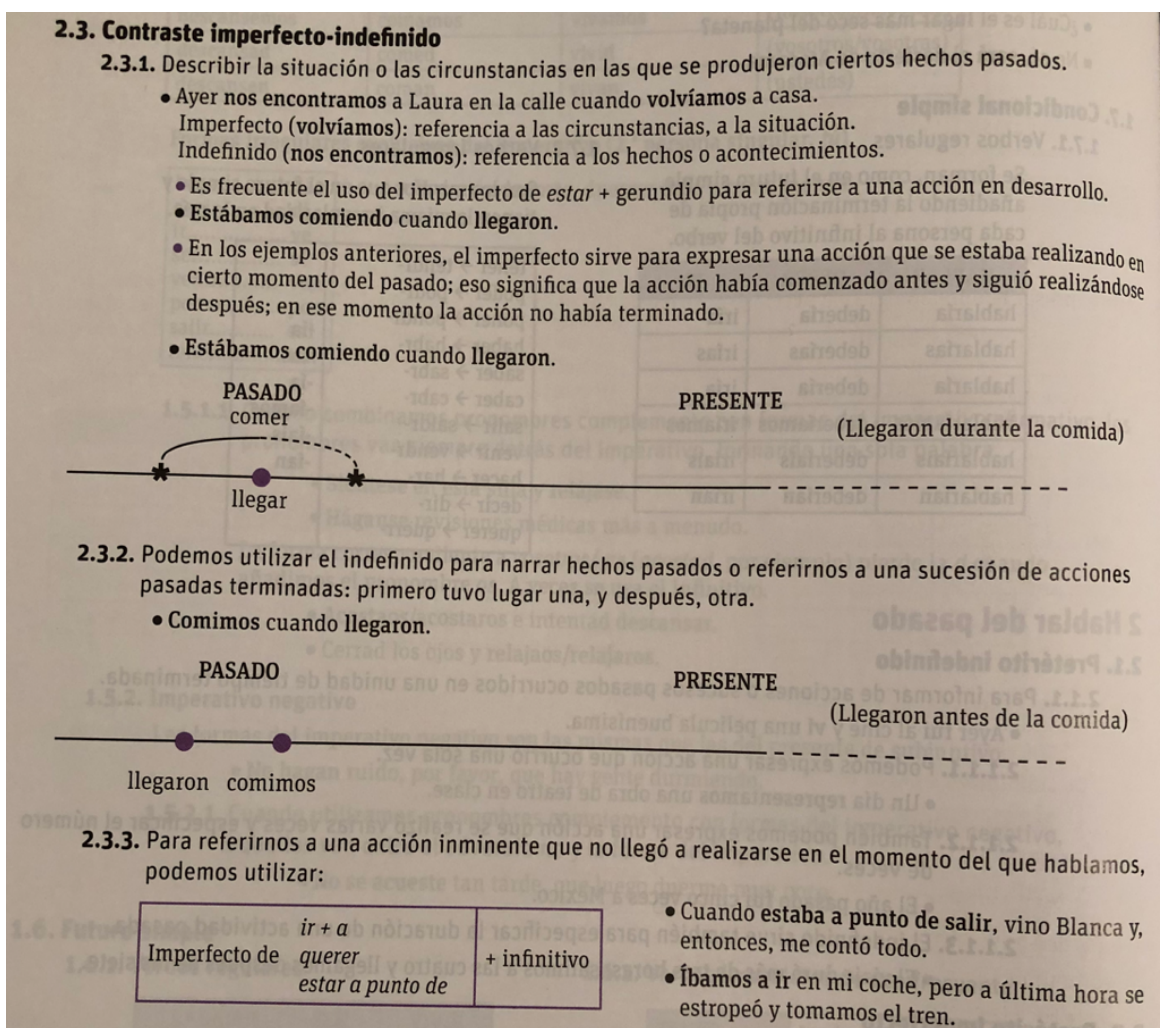

Imagen 17. Contraste de pasados en el apéndice gramatical de ELE Actual B1 (S\&M)

El input aparece marcado en los apéndices gramaticales (no en los ejemplos que surgen en el manual (en los textos o en algunas de las actividades) y en ningún caso es estructurado. 


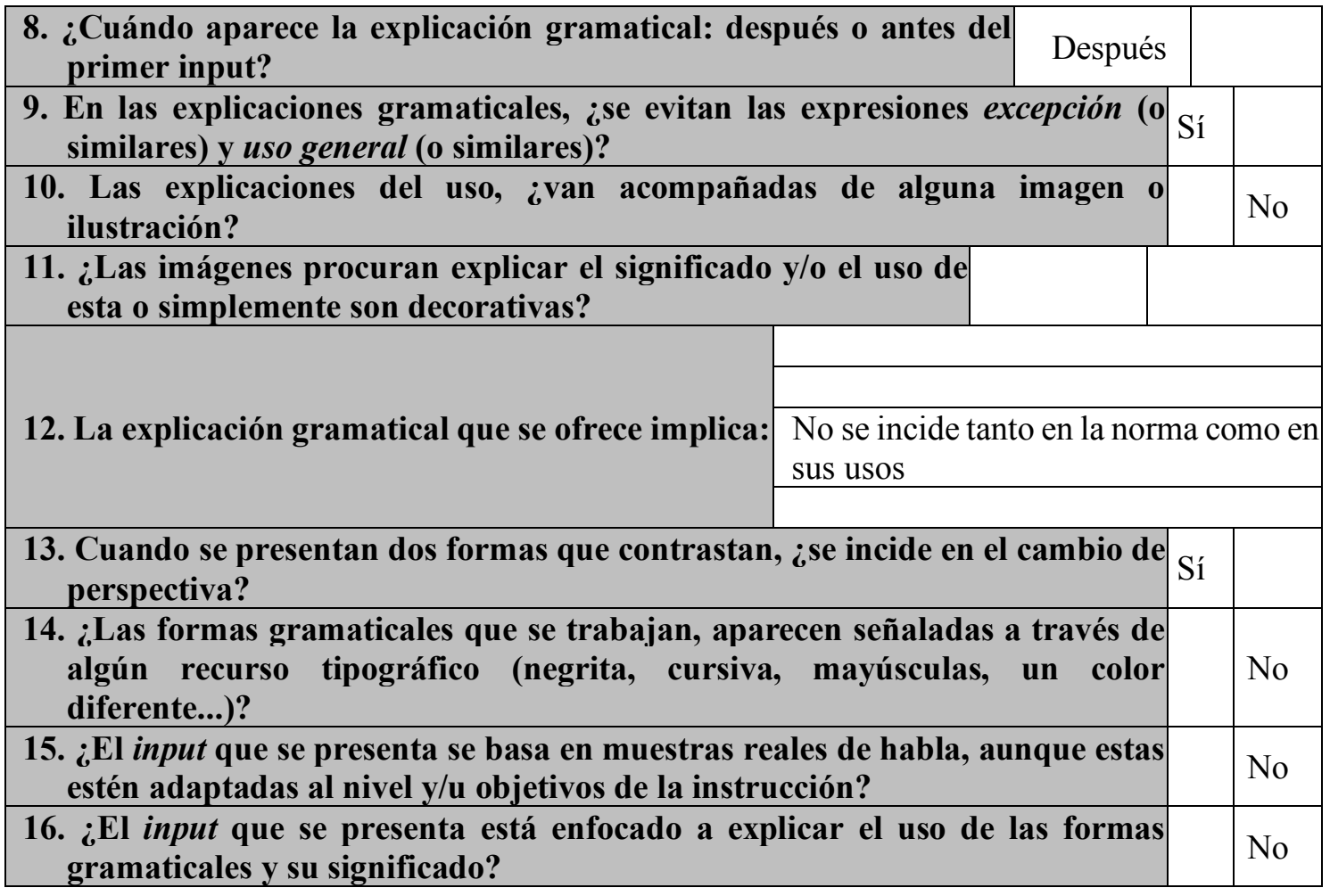

Tabla 14. Bloque 2: Presentación de la gramática en ELE Actual B1 (S\&M)

En cuanto a las actividades, ninguna de ellas ofrece los planteamientos sugeridos por la metodología de la GC: son actividades de práctica libre, no aparecen ejercicios que fomenten la conciencia gramatical, no son de output estructurado ni de asentamiento gramatical. En la imagen 15 se presenta una actividad que ejemplifica el tipo de ejercicios de producción de este manual:

\section{Un poema}

- A qué temas te vas a referir (medioambiente, trabajo, educación, etc.).

- Qué vas a escribir sobre cada tema. Puedes anotar las ideas que se te ocurran.

- ¿Van a rimar algunos versos?

\section{Imagen 18. Actividad del manual ELE Actual B1 (S\&M)}

\section{7. ¿Las actividades que se proponen son de práctica controlada} o de práctica libre?

18. ¿La progresión de las actividades empieza enfocando la importancia en el contenido o en el significado de las formas $y$, poco a poco, van incidiendo más en la construcción de las formas?

19. ¿Las actividades que se proponen son de input estructurado?

20. ¿Las actividades que se proponen son de toma de conciencia gramatical?

21. Si la respuesta anterior es sí, ¿de qué tipo?

22. ¿Las actividades que se proponen son de output estructurado?

23. ¿Las actividades que se proponen son de gramaticalización?

\section{Controlada}

Tabla 15. Bloque 3: Actividades en ELE Actual B1 (S\&M) 


\section{Conclusiones}

A partir de los anteriores análisis, hemos llegado a las siguientes conclusiones:

En primer lugar, se concluye que, de los materiales analizados, el que se compone de mayor contenido centrado en la GC es la Gramática básica del estudiante de español (Difusión), tanto en las explicaciones gramaticales como en las actividades que se presentan para trabajar las formas.

También se ha llegado a comprobar que, en la actualidad, la mayoría de los métodos que proponen las distintas editoriales especializadas en ELE recurren a las GC para los planteamientos gramaticales y las prácticas de estas formas.

Por otro lado, se ha demostrado que no todos los manuales que presentan formas gramaticales atendiendo a la GC plantean actividades que siguen esta metodología. No es lo más habitual, pero en algunos métodos el enfoque cognitivista se limita a las explicaciones del significado y/o el uso de las formas gramaticales, no en su práctica, eludiendo que esta es forma esencial del aprendizaje de la gramática.

Por último, hemos podido verificar que la ficha de análisis que se presenta en este trabajo sirve como herramienta para analizar qué manuales (o materiales) siguen en mayor o menor medida este planteamiento metodológico y en qué manera.

\section{Bibliografía}

CÁCERES RiQuelme, Bárbara. 2018. «Contraste entre pretérito imperfecto y pretérito perfecto simple o indefinido en ELE», Contextos. Estudios de Humanidades y Ciencias Sociales, 40.

CASTAÑEDA CASTRO, Alejandro. 2006. «Aspecto, perspectiva y tiempo de procesamiento en la oposición imperfecto/indefinido en español. Ventajas explicativas y aplicaciones pedagógicas», RAEL: revista electrónica de lingüistica aplicada, 5, 107-140.

CONSEJO DE EUROPA. 2002. Marco común europeo de referencia para las lenguas: aprendizaje, enseñanza, evaluación. Madrid: Ministerio de Educación y Cultura; Instituto Cervantes; y Editorial Anaya.

FERNÁNDEZ MONTES, Isabel María. 2011. «Cómo poner en práctica la atención implícita a la forma», MarcoELE, 13, 1-10.

Funes, María Soledad y Poggio, Anabella L. 2018. «La enseñanza de los tiempos verbales en la escuela secundaria: el caso de la oposición pretérito perfecto simple versus pretérito imperfecto», Lenguaje y textos, 47, 95-110.

LAKOFF, George y JoHnSON, Mark. 1986. Metáforas de la vida cotidiana. Madrid: Cátedra.

LAM, Yvonne. 2009. «Applying Cognitive Linguistics to teaching the Spanish prepositions por and para», Language Awareness, 18: 1, 2-18.

LlOPIS-GARCíA, Reyes. 2011. Gramática Cognitiva para la enseñanza de español como lengua extranjera. Madrid: Ministerio de Educación.

LLOPIS-GARCÍA, Reyes. 2015. «Las preposiciones y la metáfora de espacio: aportaciones y potencial de la lingüística cognitiva para su enseñanza», Journal of Spanish Language 
Teaching, Vol. 2, № 1, 51-68.

LlOPIS-GARCÍA, Reyes. 2019. «Gramática Cognitiva y selección modal en la enseñanza del español LE/L2». En I. Ibarretxe Antuñano, T. Cadierno, A. Castañeda Castro y J. Muñoz Basols (eds.), Lingüística Cognitiva y Español LE/L2. London: Routledge.

Llopis-GarcíA, Reyes, ReAl EsPinosA, Juan Manuel y Ruiz CAMPILlo, José Plácido. 2012. Qué gramática aprender, qué gramática enseñar. Madrid: Edinumen.

LONG, Michael H. 1988. «Instructed interlanguage development». En L. Beebe (ed.), Issues in Second Language Acquisition: Multiple Perspectives. Rowley, MA: Newbury House, 115-141.

LONG, Michael H. 1991. «Focus on form: a design feature in language teaching methodology». En K. DeBot, R. Ginsberg y C. Kramsch (eds.), Foreign Language Research in Crosh-Cultural Perspectives. Amsterdam: John Benjamins, 39-52.

LONG, Michael H. 2007. Problems in SLA. New Jersey: Lawrence Erlbaum Associates.

Long, Michael H. y RoBInson, P. 1998. «Focus on form: Theory, research, and practice». En Doughty, C. y Williams, J. (eds.), Focurs on Form in Classroom Second Language Acquisition. Nueva York: Cambridge University Press.

MiQuEL, Lourdes y ORTEGA, Jenaro. 2014. "Actividades orientadas al aprendizaje explícito de recursos gramaticales en niveles avanzados de E/LE». En A. Castañeda Castro (coord.), Enseñanza de Gramática avanzada de ELE. Criterios y recursos. Madrid: SGEL, 89-178.

Palacio Alegre, Blanca. 2016. «Gramática Cognitiva-operativa: limitaciones de una instrucción única. El caso de imperfecto/indefinido en el aula de ELE», Marco ELE, 22, $1-126$.

REAL ESPINOSA, Juan Manuel. 2005. «Tiempo y aspecto verbal: marco teórico para la clase de ELE», Marco ELE, 1, 1-32.

REAL ESPINOSA, Juan Manuel. 2013. «Una revisión crítica de la enseñanza de los tiempos de pasado: ¿son ciertas las reglas que prescribimos?». En Actas del I Congreso Internacional de Didáctica de Español como Lengua Extranjera, 621-633.

RuIZ CAMPILlO, José Plácido. 2005. «Instrucción indefinida, aprendizaje imperfecto. Para una gestión operativa del contraste imperfecto/indefinido en clase», Mosaico. Revista para la promoción y apoyo a la enseñanza del español, 15, 9-17.

RuIZ CAMPILlO, José Plácido. 2007a. «El concepto de declaración como valor de subjuntivo. Protocolo de instrucción operativa de la sección modal en español». En Actas del programa de formación para profesorado de ELE 2005-2006 del Instituto Cervantes de Munich, 285-327.

Ruiz CAMPILlo, José Plácido. 2007b. «¿El subjuntivo es lógico?», MarcoELE. Material interactivo en formato SCORM.

Ruiz CAMPILlO, José Plácido. 2012. «The Subjuntive in a single concept: Teaching an operational approach to Mood Selection in Spanish». En G. Ruiz Fajardo (ed.), Methodological Developments in Teaching Spanish as a Second and Foreign Language. Cambridge: Cambdridge Scholars, UK, 273-330.

RuIZ CAmPILlo, José Plácido. 2014. «El subjuntivo es lógico. Una actividad de 
concienciación», Redele, 1.

RuIz CAMPILlO, José Plácido. 2017. «El verbo como espacio: seis nuevos temas de gramática del español», Revista Nebrija de Lingüística Aplicada, 22.

SALAS DíAZ, Miguel. 2011. «Un acercamiento cognitivo al problema del subjuntivo», Actas del Congreso de AEPE, 46, 173-183.

SOLÁ SIMÓN, Elena. 2020. «Una aplicación empírica de la gramática cognitiva-operativa a la enseñanza del contraste modal en español (como lengua extranjera)», MarcoELE, suplemento $31,70-90$.

VAnPATTEN, Bill. 2007. «Input processing in adult Second Language Acquisition». En B. VanPatten y J. Williams (eds.), Theories in Second Langauge Acquisition: An Introduction. New Jersey: Lawrence Erlbaum, 115-136.

WILK-RACIESKA, Joanna. 2000. «Tiempo real y tiempos gramaticales: presente e imperfecto de indicativo», ELUA, 14, 275-290. 